\title{
Forecaster Evaluations of High Temporal Satellite Imagery for the GOES-R Era at the NWS Operations Proving Ground $\mathscr{A}$
}

\author{
Chad M. GRAVELle \\ NOAA/NWS/Operations Proving Ground, Kansas City, Missouri, and Cooperative Institute for Meteorological \\ Satellite Studies, University of Wisconsin-Madison, Madison, Wisconsin \\ KIM J. RUNK \\ NOAA/NWS/Operations Proving Ground, Kansas City, Missouri \\ KATIE L. CRANDAll AND DERRICK W. SNYdeR \\ NOAA/NWS/Operations Proving Ground, Kansas City, Missouri, and Cooperative Institute for Mesoscale \\ Meteorological Studies, University of Oklahoma, Norman, Oklahoma
}

(Manuscript received 3 October 2015, in final form 1 April 2016)

\begin{abstract}
Between February and April of 2015, the National Weather Service (NWS) Operations Proving Ground (OPG) facilitated an evaluation of the usefulness of 1-min satellite imagery for NWS operations in the Geostationary Operational Environmental Satellite-R (GOES-R) series era. The overarching goal of the evaluation was to provide quantitative and qualitative guidance to NWS management, including the regional NWS Scientific Services division chiefs, on how satellite imagery with a refresh rate of $1 \mathrm{~min}$ impacts NWS forecaster decision-making. During the simulations, forecasters evaluated 1- and 5-min satellite imagery while completing tasks ranging from aviation forecasting and wildfire decision support services to monitoring where convective initiation would occur and integrating the imagery into the convective warning decision-making process. Feedback was gathered to assess if the satellite imagery had influence on forecaster decision-making, if the satellite imagery provided them with more confidence in making those decisions, if forecasters could assimilate the data into operational practices, and if there were adverse impacts on forecaster workload. Forecasters overwhelmingly were of the opinion that 1-min satellite imagery improved their ability and increased their confidence to make effective forecast and warning decisions. The majority of participants expressed that they were able to internally assimilate the imagery with ease. However, feedback gathered when forecasters were asked how useful and easy the imagery was to use in convective warning operations was mixed. Some forecasters expressed difficulty integrating both satellite imagery and radar data while issuing convective warnings. Others felt that with ample training and experience the imagery would be invaluable in warning operations.
\end{abstract}

\section{Introduction}

The next generation of the Geostationary Operational Environmental Satellite (GOES) series, GOES-R, is scheduled for launch in October 2016 and will offer

Supplemental information related to this paper is available at the Journals Online website: http://dx.doi.org/10.1175/ WAF-D-15-0133.s1.

Corresponding author address: Chad Gravelle, NOAA/NWS/ Operations Proving Ground, 7220 NW 101st Terr., Kansas City, MO 64153.

E-mail: chad.gravelle@noaa.gov improved spacecraft and instrument technology to provide more accurate, detailed, and timely detection of environmental phenomena. The GOES-R series will feature the Advanced Baseline Imager (ABI; Schmit et al. 2005), a 16-channel imager with 2 visible channels, 4 near-infrared (IR) channels, and 10 IR channels. The ABI will provide 3 times more spectral information, 4 times the spatial resolution, and 5 times the temporal resolution when compared to the current GOES imager.

Since 2012, the GOES-14 imager has occasionally been placed in experimental super rapid scan operations for GOES-R (SRSOR; Schmit et al. 2013) to emulate the high temporal resolution sampling of the ABI. 
During the GOES-14 SRSOR experiments, numerous atmospheric phenomena have been observed, including fog and low stratus, convection, fires and smoke, and tropical cyclones (Schmit et al. 2013, 2015). Some National Weather Service (NWS) forecasters have had the opportunity to evaluate the high temporal satellite imagery in the testbed environment (e.g., Line 2014; Terborg 2014). For example, forecasters participating in the 2014 Hazardous Weather Testbed's Experimental Warning Program consistently said 1-min satellite imagery had a positive impact on their situational awareness and the warning decision-making process (Line 2014). Other NWS forecasters, including those at the Storm Prediction Center (SPC; Line et al. 2016) and Weather Prediction Center, have used high temporal satellite imagery directly for operational decisionmaking. At the SPC, forecasters have stated 1-min satellite imagery has assisted with severe thunderstorm and tornado watch decision-making (Line et al. 2016).

While feedback within the National Oceanic and Atmospheric Administration (NOAA) test beds and operational centers was overwhelmingly positive, it is important to build upon these results in a setting where NWS forecasters replicate their normal workflow in a realistic Weather Forecast Office (WFO) environment. The NWS Operations Proving Ground (OPG) was developed to serve as such a facility (NOAA 2013). The OPG's mission is to complement existing NOAA test beds and proving grounds, where new tools, techniques, and capabilities are assessed for scientific integrity and reliability. Once a level of maturity is demonstrated, the OPG is engaged to complete "last mile" evaluations in which NWS forecasters are asked to integrate these new capabilities into their workflow on an Advanced Weather Interactive Processing System (AWIPS) that is configured using baseline hardware and software structures. In this environment, forecasters assess the value added to their operational decision-making, potential improvements to situational awareness, risk communication, etc., and the impact on workload using live data or displaced real-time simulations. To achieve endorsement for field implementation, a new capability must demonstrate unique value to the forecast process while having minimal adverse impact on human factors.

From February through April 2015, the NWS OPG hosted a series of six week-long evaluations to assess the operational impact of high-temporal-resolution satellite imagery. The overarching goal of the evaluation was to provide quantitative and qualitative guidance to NWS senior leadership on how 1- and 5-min-resolution satellite imagery impacts the NWS forecaster's ability to make effective forecast and warning decisions within the context of convective and nonconvective situations. During each weekly session, NWS forecasters completed seven realistic WFO simulations that integrated 1- and 5-min-resolution satellite imagery, similar to what will routinely be available in the GOES-R era, into a variety of analysis, forecast, and warning tasks, in a diverse range of geographic locations (Fig. 1). The purpose of this paper is to present the observations and insights gleaned from those NWS forecasters' experiences integrating high-temporal-resolution satellite imagery into their routine production cycle.

\section{Participant selection and assessment methodology}

NWS forecasters were selected to participate in the OPG 1-min satellite imagery evaluation by the four continental United States (CONUS) NWS Regional Offices. This resulted in a group of 17 forecasters that included three females and fourteen males from NWS WFOs located in the Eastern (4 forecasters), Central (5 forecasters), Southern (2 forecasters), and Western Regions (6 forecasters; Fig. 1). Years of NWS work experience between the six journey forecasters, seven lead forecasters, and one science and operations officer ranged from 4 to 29, with an average of 14 years of service. These participants represented a broad cross section of NWS forecasters that was important to obtain when evaluating a capability that will impact the NWS operational workforce. Three NWS forecasters participated in each of the six week-long evaluation sessions, except for the last week when only two participated because one was forced to cancel because of a family emergency. Although participating forecasters had at least four years of experience in the NWS, it is likely they have varying levels of experience using satellite imagery in the forecast process. Therefore, before arriving at the OPG for the evaluation, each participating forecaster was assigned Schmit et al. (2013) to read, along with four self-paced learning modules that provided an overview on GOES-R, 1-min satellite imagery applications for severe thunderstorms, and information on using the GOES-R overshooting top (OT; Bedka et al. 2012; Dworak et al. 2012) and convective cloud-top cooling (CTC; Sieglaff et al. 2011, 2014) algorithm output. The goal was to establish a baseline level of familiarity with the datasets being featured in the OPG evaluation.

In the GOES-R era, high temporal satellite imagery may be the primary dataset that guides some forecaster decisions, while for others satellite imagery will likely play an important supporting role. For example, during the convective warning decision-making process, although 1-min satellite imagery may enhance a forecaster's understanding and confidence of storm-scale evolution, forecasters primarily use WSR-88D data to drive their warning decisions. Therefore, instead of 


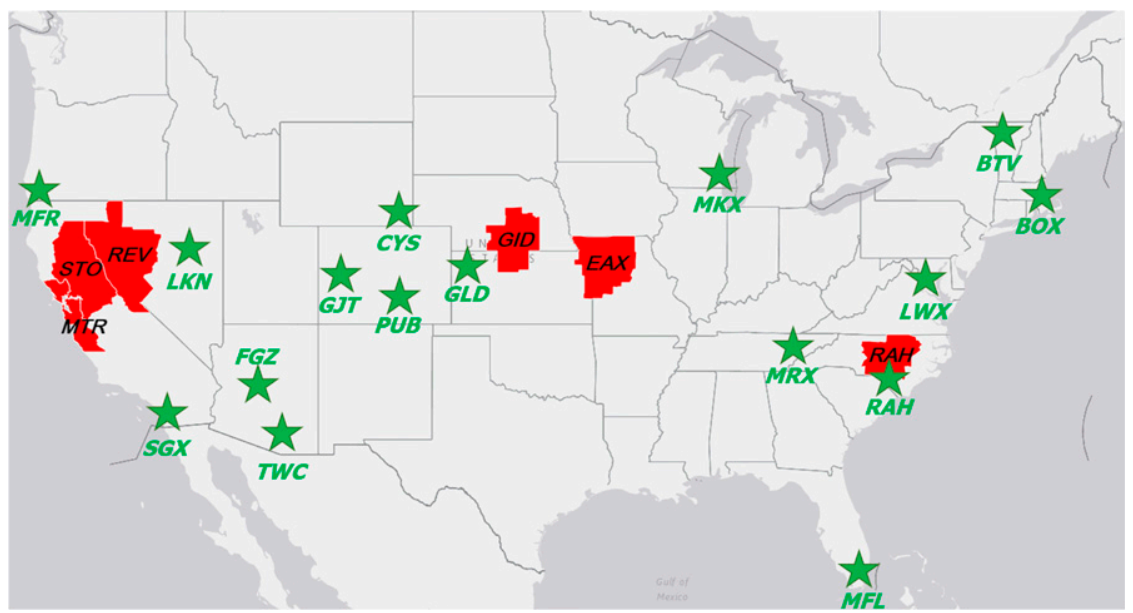

FIG. 1. Environmental Systems Research Institute, Inc. (Esri), ArcGIS software map of evaluation participants' home WFO locations (green stars), and NWS CWAs (shaded red) where participants completed evaluation simulations.

placing emphasis on quantitative improvements with warning and forecast lead times while incorporating the high temporal satellite imagery, it was more important to focus this evaluation on capturing the forecaster's conceptual understanding, reasoning, and decision-making.

Over the last 15 years, several studies have successfully used cognitive task analysis (Crandall et al. 2006) to understand NWS forecaster decision-making. These investigations have ranged from an examination of concepts related to decision-making during a tornado outbreak in Oklahoma (Andra et al. 2002) to, more recently, an investigation into whether increasing the temporal resolution of radar data leads to better forecaster decisions (Bowden et al. 2015). For a thorough discussion of analyzing forecaster decision-making, the reader is directed to Heinselman et al. (2012). For this evaluation, four methods were used to extract the forecaster's conceptual understanding, reasoning, and decision-making: web-based decision logs, recent case walk-throughs (RCWs; e.g., Heinselman et al. 2015), small-group discussions, and a comprehensive anonymous online survey. These methods will be discussed in more detail below.

Similar to the confidence ratings participants utilized in Bowden et al. (2015), participating forecasters used a real-time web-based decision log to quickly document the decisions as they were made, their confidence in those decisions, and their reasoning behind them. These decisions may have ranged from issuing a convective warning, to updating a terminal aerodrome forecast (TAF), to notifying relevant NWS partners via NWSChat of imminent high-impact weather. The decisions were logged to provide facilitators with insight on what participating forecasters were observing, doing, and thinking while completing each simulation in real time. In addition, for the convective initiation (CI), convective warning operations, and mesoanalyst simulations, these decisions were used to develop each forecaster's initial decision-making timeline, which was used in a cognitive task analysis retrospective method called the RCW.

The RCW method was successfully applied by Heinselman et al. (2015) in the Phased Array Radar (PAR) Innovative Sensing Experiments. In Heinselman et al. (2015), the forecaster's desktop was recorded using the RecordMyDesktop software, and facilitators completed the RCW with participants using three sweeps or passes as they were presented with a playback of their recorded actions; one sweep built the decision-making timeline, another refined the timeline, and the third deepened the timeline. As the sweeps were completed, PAR forecasters were asked to recollect what they were seeing, thinking, and doing during the simulation while facilitators documented their thought processes. In the OPG evaluation, RCWs were completed similarly to the method used by Heinselman et al. (2015) with the main difference being that the decisions documented by forecasters in real time using the web-based decision log were used as the basis for developing the initial decisionmaking timeline. OPG facilitators could then deepen the timeline in a single rigorous one-on-one interactive discussion with participants as they reviewed their recorded actions. This modification was adopted to balance the time allocated for cognitive task analysis with the requirement to evaluate the high temporal satellite imagery for a variety of analysis and forecast applications. Although it may be argued that using the web-based decision log for developing the initial decisionmaking timeline is less thorough than the original RCW method, there is no evidence this adaptation had 
TABLE 1. List of simulations participating forecasters completed during each of the six evaluation weeks.

\begin{tabular}{|c|c|c|c|}
\hline Simulation & Date & Time (UTC) & NWS CWA \\
\hline Convective initiation $^{\mathrm{a}}$ & 10 May 2014 & $1840-2010$ & Pleasant Hill, MO \\
\hline Convective warning operations ${ }^{\mathrm{a}}$ & 10 May 2014 & $2100-2230$ & Pleasant Hill, MO \\
\hline Mesoanalyst & 18 Aug 2014 & $2100-2230$ & Raleigh, NC \\
\hline Monsoon flash flooding & 14 Aug 2014 & $1730-1900$ & Las Vegas, NV \\
\hline Severe Weather Outbreak & 11 May 2014 & $1815-2200$ & Hastings, NE \\
\hline Wildfire and air quality support ${ }^{\mathrm{a}}$ & 22 Aug 2013 & $1645-1815$ & Reno, NV, and Sacramento, CA \\
\hline Fog and low-stratus aviation support ${ }^{\mathrm{a}}$ & 22 Aug 2013 & $1630-1800$ & Monterey Bay, CA \\
\hline
\end{tabular}

${ }^{\text {a }}$ Discussed in section 3 .

substantive adverse impacts on the content. The modified RCW methodology still provides an opportunity to document the qualitative thought process of the forecaster with more accuracy and depth than many other methodologies.

After each simulation, a small-group discussion was conducted with the forecasters to review their experiences with the high temporal satellite imagery and how they integrated this tool into their forecast and warning processes. Emphasis was placed on having forecasters articulate details concerning the usefulness of the 1-min imagery, interesting or unexpected ways it contributed to aspects of their decision-making, insights gained from fusing the imagery with other datasets, and their ability to assimilate the data effectively for the assigned task. The discussions were recorded and detailed accounts were extracted to provide an additional layer of forecaster assessment. Finally, on each Friday morning, forecasters completed an anonymous comprehensive survey that allowed them to rate and discuss their experiences using the satellite imagery. The results presented in sections 3 and 4 are a combination of the four methods discussed here.

\section{Evaluation simulations and key forecaster observations}

To achieve the most comprehensive assessment of the high-temporal-resolution satellite imagery, it was important to select cases for each simulation that would represent a variety of meteorological phenomena and forecasting tasks. Therefore, forecasters evaluated the 1-min satellite imagery with tasks that ranged from monitoring CI for impact on TAFs to providing critical impact-based decision support services (IDSS) during a high-impact wildfire. Each week, forecasters completed the simulations (Table 1) in the same order and on the same days to minimize any potential biases. In addition to the simulations listed in Table 1 , for $90 \mathrm{~min}$ on each Monday morning, participating forecasters became familiar with OPG systems and the datasets they would have access to during the evaluation simulations.
Using a displaced real-time severe weather event across Minnesota and Iowa, the intent of the training simulation was to ensure forecasters became comfortable finding datasets in AWIPS, issuing convective warnings using the AWIPS Warning Generation (WarnGen) software, and understanding how to fuse gridded datasets with 1-min satellite imagery.

In each simulation, forecasters received satellite imagery that was collected during the 2013 and 2014 SRSOR experiments. This imagery was used as a proxy (i.e., 26 consecutive images every $30 \mathrm{~min}$ ) for the temporal resolution that will be available with the ABI on GOES-R. In addition, the satellite image latency to the forecaster during the simulations was similar to what it would be during the GOES-R era [i.e., approximately $45 \mathrm{~s}$ for a 1-min resolution domain; NOAA (2015)]. Although not possible to simulate during this evaluation, in addition to the temporal resolution improvements on the ABI, the spatial resolution on GOES-R will be improved by a factor of 4 . Other datasets forecasters received during each simulation, unless specifically discussed, were WSR-88D level II base data and dual-polarization variables from sites within the simulation County Warning Area (CWA), aviation routine weather reports (METARs) surface weather reports, High-Resolution Rapid Refresh (HRRR) model output, and Rapid Refresh (RAP) model output. During the mesoanalyst, monsoon flash flooding, and severe weather outbreak simulations, GOES-R OT (Bedka et al. 2012; Dworak et al. 2012) and CTC (Sieglaff et al. 2011, 2014) algorithm output using SRSOR data was also provided to participating forecasters.

Before each simulation began, participating forecasters viewed a prerecorded weather briefing that attempted to provide each forecaster with an understanding of the meteorological environment along with their roles and responsibilities for the simulation. Once the weather briefing finished, participating forecasters began each simulation in displaced real time. The remainder of this section will focus on forecaster observations from the CI, convective warning operations, wildfire and air quality, and fog and low-stratus simulations. 


\section{a. Convective initiation}

This simulation occurred in the Kansas City/Pleasant Hill, Missouri (EAX), NWS CWA on 10 May 2014 between 1840 and 2010 UTC (a satellite animation of this simulation is available in the online supplemental material for this article). At the start of the simulation, a cumulus field was present across the western portion of the EAX CWA and an SPC mesoscale discussion was given to the participants that stated "rapid intense thunderstorm development appears possible by around 20-21Z..." During the second half of the simulation, agitated cumulus clouds developed across southeastern Nebraska and northwestern Missouri that resulted in two significant thunderstorms (Fig. 2). The thunderstorm that developed across northwestern Missouri produced 1.75-in. hail.

Forecasters were instructed to work individually and monitor the CWA for CI, issue any necessary NWS products, including how convective evolution may impact the TAFs for three NW Missouri airports (Rosecrans Memorial Airport, St. Joseph, Missouri; Kansas City International Airport, Kansas City, Missouri; and Charles B. Wheeler Downtown Airport, Kansas City, Missouri), and communicate potential hazards to any appropriate NWS partners. All products were issued with either the AWIPS WarnGen or the Aviation Forecast Preparation System (AvnFPS) software packages.

Animating 1- and 5-min satellite imagery, in near real time, was deemed extremely valuable for visualizing and understanding three-dimensional atmospheric flow and, in particular, the evolution of cumulus growth and convection. Forecasters continuously mentioned that these animations revealed many insightful details about fluid atmospheric motions and finescale cloud interactions that are nearly impossible to perceive in lower temporal resolution imagery (i.e., 15-min imagery or greater). For example, animating $1-\mathrm{min}$ visible $(0.65 \mu \mathrm{m})$ satellite imagery made it possible to identify the appearance of cirrus spissatus clouds or "orphan anvils", (Bluestein et al. 1990; Line et al. 2016) and understand how to interpret their significance within the context of CI. Here, an orphan anvil is associated with an updraft that briefly penetrates a stable layer, but cannot maintain the strong, deep vertical motion field necessary to continue developing into a mature cumulonimbus cloud. Once such an updraft decouples from the boundary layer, the midlevel cirrus spissatus cloud is carried downstream by the environmental wind. Being able to identify the presence of orphan anvils can be extremely useful when anticipating CI because it is evidence of a local weakness in convective inhibition and may serve as a signal that deep, moist convection is imminent. The high-temporalresolution satellite imagery allowed forecasters to recognize this phenomenon as it was occurring and trace the process back to its source, enabling identification of specific locations to scrutinize for CI.

A number of forecasters noted that analyzing cloud-top temperatures from IR $(10.7 \mu \mathrm{m}) 1$ - and 5-min satellite imagery was useful in identifying which convective updrafts were growing most rapidly. For example, between 1915 and 1931 UTC cloud-top temperatures of the convective updraft in northwestern Missouri rapidly cooled (Fig. 2), and the high temporal satellite imagery allowed forecasters to quickly determine that CI was most likely in this area. One forecaster discussed the usefulness of the IR imagery for CI after completing this simulation:

"In this simulation, I used the visible more than the IR but the IR definitely had some useful information. Initially, I used the visible to observe the bubbling cumulus to see initial development. Then as the towers began to grow I could observe them in the IR imagery. It gave me confirmation that these towers are strong and things are starting to get going here."

Another forecaster mentioned the transition from visible to IR imagery:

"Once things started to show up on radar and became mature enough to show up in IR [imagery], I was able to compare the storms and their heights. Once things get going and became muddled on visible, IR [imagery] becomes a lot more useful."

Most forecasters noted that the ability to observe these types of features (e.g., orphan anvils and rapidly growing updrafts) and make mental connections to their conceptual models led directly to improving their situational awareness and operational decisions. For example, one forecaster stated:

"Seeing it [the 1-min satellite imagery], using it, and experiencing it in the warning setting, you don't realize how much you are missing. That was the big eye opening moment for me, seeing rapid development that we are missing with current scanning strategies."

This comment is illustrative of several opinions shared during discussions, in which participants noted how effortlessly they were able to identify atmospheric processes that are difficult, if not impossible, to identify with $G O E S-13 / 14 / 15$ series $15-m i n$ satellite imagery.

Some forecasters attributed better forecast decisions and greater lead time to the 1-min satellite imagery. For example, by tracking the leading edge of the agitated cumuli, forecasters could quickly determine the impact on aviation operations and, if necessary, issue timely 


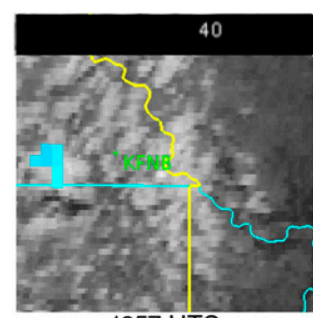

1857 UTC

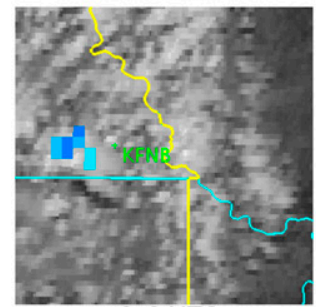

1903 UTC

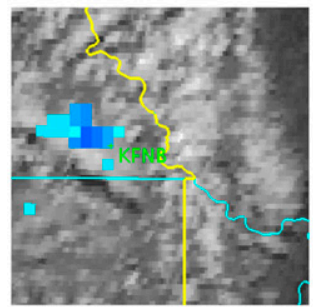

1908 UTC

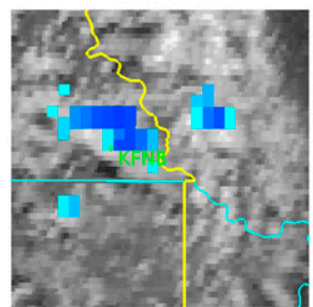

1916 UTC

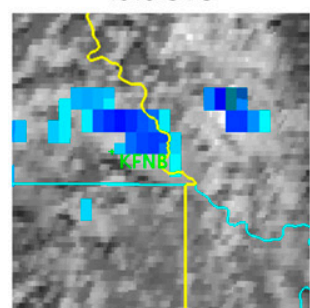

1921 UTC

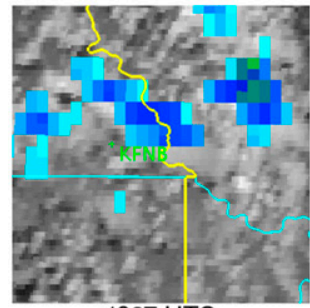

1927 UTC

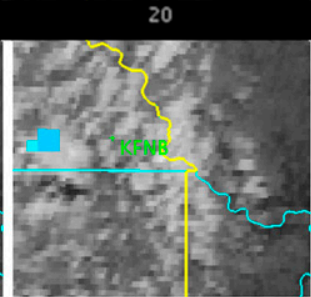

1858 UTC



1904 UTC

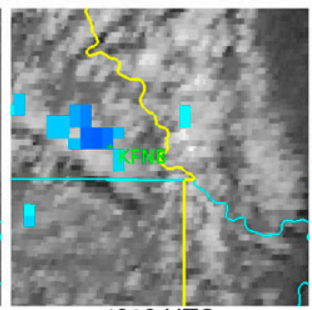

1909 UTC



1917 UTC

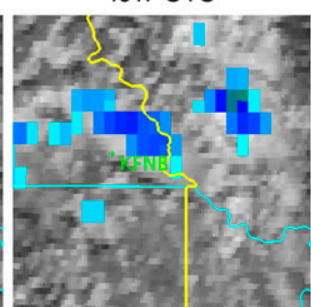

1922 UTC



1928 UTC

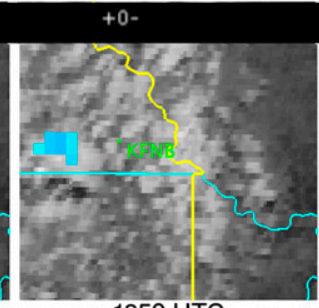

1859 UTC

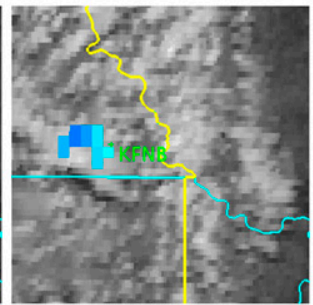

1905 UTC

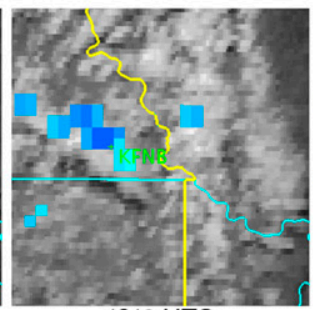

1910 UTC

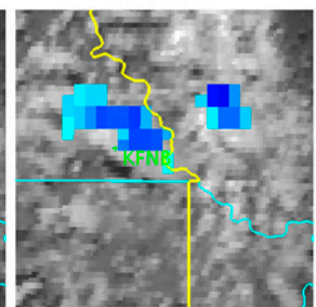

1918 UTC



1923 UTC



1929 UTC

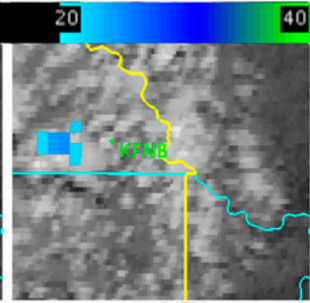

1901 UTC

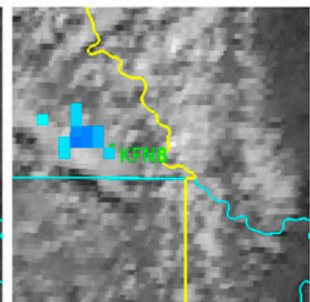

1906 UTC

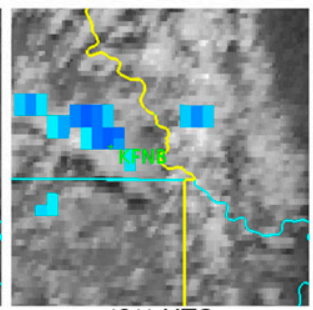

1911 UTC



1919 UTC

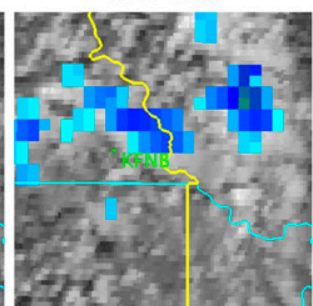

1925 UTC

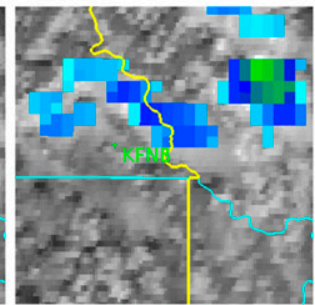

1930 UTC

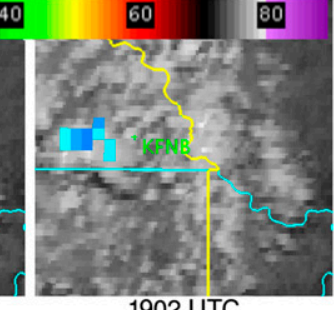

1902 UTC

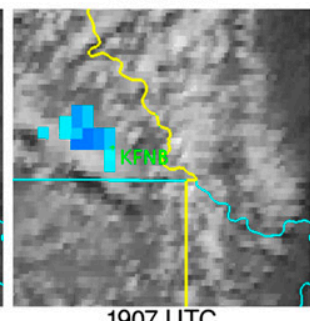

1907 UTC

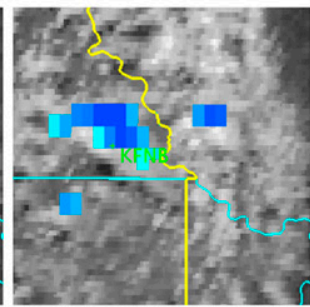

1915 UTC

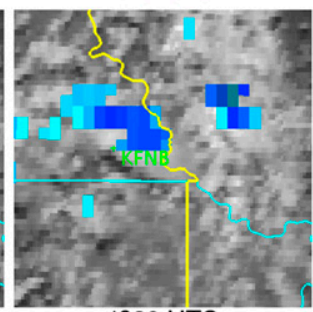

1920 UTC

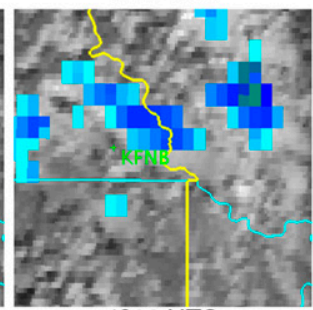

1926 UTC

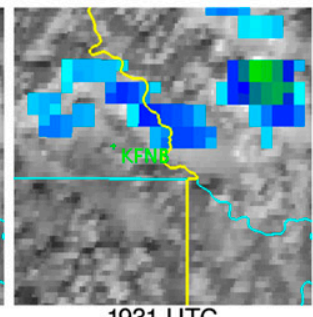

1931 UTC

FIG. 2. GOES-14 visible and infrared $10.7-\mu \mathrm{m}$ satellite image $\left({ }^{\circ} \mathrm{C}\right.$; shaded according to the scale) time series of two intensifying cumulus clusters between 1857 and 1931 UTC (i.e., 30 images) 10 May 2014 from the convective initiation simulation. GOES-14 routine operations images have times identified in red text, and animations of GOES-14 super rapid scan and routine operations between 1840 and 2010 UTC are available in the online supplemental material. 


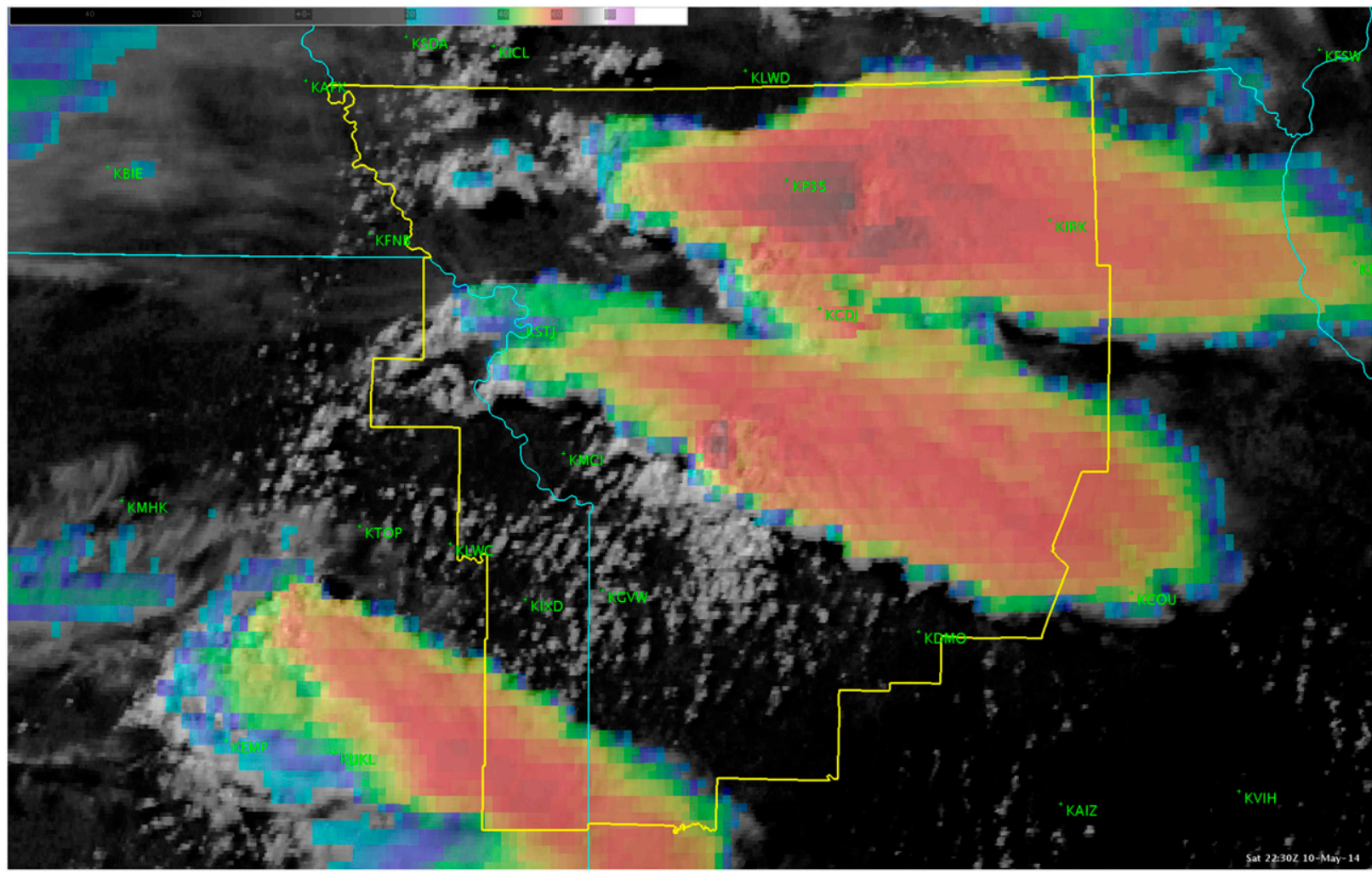

FIG. 3. GOES-14 visible and infrared $10.7-\mu \mathrm{m}$ satellite image $\left({ }^{\circ} \mathrm{C}\right.$; shaded according to the scale) valid at $2230 \mathrm{UTC} 10 \mathrm{May} 2014$ from the convective warning operations simulation. The Pleasant Hill NWS CWA boundary is shown (yellow), and an animation between 2100 and $2230 \mathrm{UTC}$ is available in the online supplemental material.

amendments to the impacted TAF sites well before radar echoes would suggest a reason for concern. Some forecasters credited the high-temporal-resolution imagery with enabling them to anticipate how the shortterm forecast would evolve:

"[This allowed me to] get ahead of the game by composing social media posts, informing EMs and media partners via NWSChat, and performing other DSS activities to be better prepared to take on warning responsibilities. [...] Without this type of real-time, rapid refresh animation, I would have been reacting to initial development [on radar] and trying to catch up once we shifted to warning mode."

Another forecaster discussed a similar experience:

"My workflow completely changed by watching this coming together in near real-time. I started to put out special media products, updated AFDs, amended TAFs before ever seeing anything on radar. My normal workflow at the office would be to see something on radar and scramble to get everything else out after getting that confirmation."

These statements are significant because it has been hypothesized that increasing the temporal resolution of satellite imagery may place stress on the operational forecaster's workload. For this forecaster, the opposite occurred as the 1-min satellite imagery allowed for better anticipation of the initial convective development, which in turn placed less stress on workload.

\section{b. Convective warning operations}

This simulation occurred in the EAX NWS CWA on 10 May 2014 between 2100 and 2230 UTC, 50 min after the CI simulation ended (Fig. 3; a satellite animation of this simulation is available in the online supplemental material). When the simulation began, an SPC severe thunderstorm watch was in effect, and severe thunderstorms were occurring across northern Missouri. Thunderstorms were also developing just north of Kansas City and quickly became severe by 2120 UTC. Forecasters were instructed to work individually, and their sole responsibility was to, if necessary, issue convective warnings for the convection developing near Kansas City. The severe thunderstorm farthest to the south moved east-northeast along a quasi-stationary surface boundary and produced hail as large as $2.50 \mathrm{in}$. and an [enhanced Fujita (EF) scale] EF-2 tornado at 2216 UTC, $14 \mathrm{~min}$ before the simulation ended. 


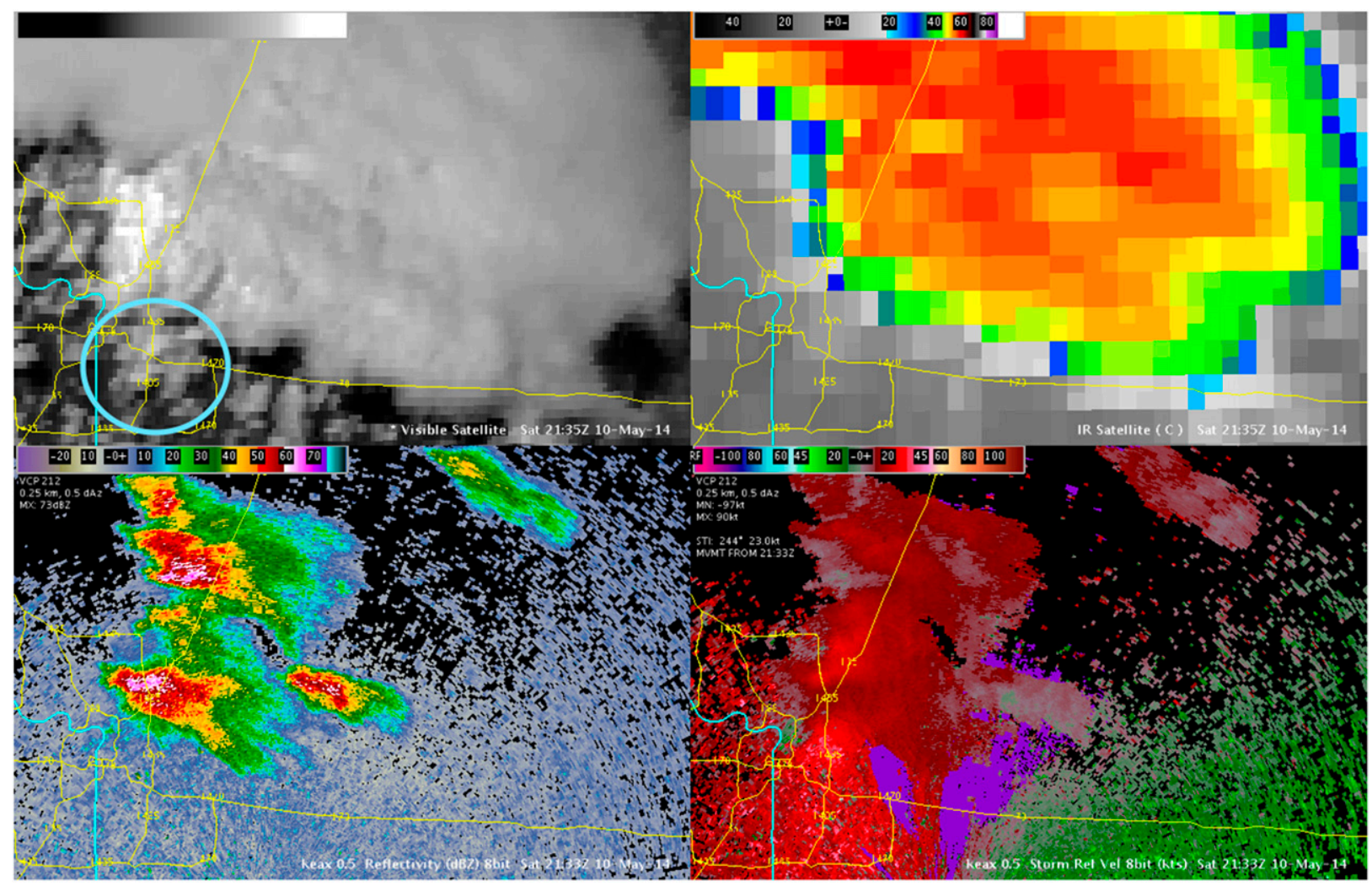

FIG. 4. (top left) GOES-14 visible satellite image valid at 2135 UTC 10 May 2014, (top right) GOES-14 infrared 10.7- $\mu \mathrm{m}$ satellite image $\left({ }^{\circ} \mathrm{C}\right.$; shaded according to the scale) valid at 2135 UTC 10 May 2014, (bottom left) WSR-88D KEAX $0.5^{\circ}$ reflectivity (dBZ; shaded according to the scale) valid at 2133 UTC 10 May 2014, and (bottom right) WSR-88D KEAX $0.5^{\circ}$ storm-relative velocity $(\mathrm{kt}$, where $1 \mathrm{kt}=$ $0.51 \mathrm{~m} \mathrm{~s}^{-1}$; shaded according to the scale) valid at 2133 UTC 10 May 2014. The blue circle (top left) identifies the feeder cloud cluster discussed in the text, and an animation between 2135 and 2159 UTC is available in the online supplemental material.

Three important observations regarding high temporal satellite observations, directly relevant to improving the convective warning decision-making process, were made by the majority of forecasters during this simulation. Each of these observations would be repeated and reinforced multiple times as the week progressed, but they were first observed while forecasters completed this simulation.

The first observation identified was that high temporal satellite imagery, especially 1-min satellite imagery, can allow forecasters to anticipate storm-scale evolution before confirming the presence of storm structures in WSR-88D data. One example occurred during this simulation as forecasters observed a feeder cloud cluster of cumulus congestus being ingested into the southernmost storm's main updraft (identified with a blue circle in Fig. 4). Feeder cloud clusters, discussed in detail in Mazur et al. (2009), are organized cumulus clusters that are situated within a thunderstorm's warm sector inflow that converge on the main updraft. In this case, forecasters observed feeder clouds that transitioned to a feeder cloud cluster just south of the thunderstorm's main updraft at approximately 2130 UTC.
Fifteen minutes later, the feeder cloud cluster was ingested into the main updraft, and between 2147 (Fig. 4) and 2159 UTC (Fig. 5) considerable cooling was observed in IR temperatures. Forecasters noted the storm's structure became more organized in radar signatures as the updraft intensified: the magnitude of the KEAX WSR-88D's $0.5^{\circ}$ reflectivity inflow gradient increased, an inflow notch developed, and moderate midlevel rotation appeared in the $0.5^{\circ}$ storm-relative velocity data. By 2159 UTC, cloud-top temperatures approached $-65^{\circ} \mathrm{C}$ (blue circle in Fig. 5, top right) and the low-level storm-relative velocity couplet continued to strengthen (yellow circle in Fig. 5, bottom right). In group discussions, forecasters hypothesized this evolution was due to the feeder cloud cluster being ingested into the main updraft and, in turn, enhancing vertical and rotational velocity. This sequence of events, shown as an animation in the online supplemental material, led one forecaster to discuss how analyzing the 1-min satellite imagery with WSR-88D data provided them with additional confidence to issue a tornado warning: 




FIG. 5. (top left) As in the top-left panel of Fig. 4, but valid at 2159 UTC 10 May 2014. (top right) As in the top-right panel of Fig. 4 top right, but valid at 2159 UTC 10 May 2014. (bottom left) As in the bottom-left panel of Fig. 4, but valid at 2201 UTC 10 May 2014 . (bottom right) As in the bottom-right panel of Fig. 4, but valid at 2201 UTC 10 May 2014. The blue circle (top right) identifies the strengthening updraft, and the yellow circle (bottom right) identifies the strengthening low-level storm-relative velocity couplet discussed in the text. An animation between 2135 and 2159 UTC is available in the online supplemental material.

"At 2158 UTC I issued a tornado warning. The circulation [on radar] continued to strengthen and I noticed enhanced velocity/inflow into the storm. The visible satellite imagery also indicated enhanced inflow feeder clouds into the storm and I felt that it was only a matter of time before this storm produces a tornado."

It is important to note most forecasters did not observe this sequence of events during the simulation. However, during postsimulation discussions, the majority of forecasters stated this was a result of not understanding the significance of how feeder cloud clusters can influence storm-scale evolution and may indicate the probability of severe weather is increasing, as discussed in Weaver and Lindsey (2004) and Mazur et al. (2009).

This example illustrates the value of integrating high temporal satellite imagery with radar interrogation to improve a forecaster's awareness of how the storm-scale landscape evolves and how the convective warning decision-making process can be enhanced. In situations where a warning forecaster can anticipate changes in storm structure by analyzing 1-min satellite imagery, some forecasters speculated that it may be possible to prepare an initial warning polygon that can be quickly transmitted if the next WSR-88D volume scan indicated a severe weather hazard is imminent. For convective warnings, this could result in a minute or two of additional lead time, which may represent a significant, perhaps life-saving, difference.

As in the CI simulation, forecasters once again found usefulness in analyzing the high-temporal-resolution IR imagery along with radar data. They continued to discuss how important it was to analyze how storm tops in mature convection were evolving. One forecaster discussed how IR cloud-top temperatures helped concentrate their attention in complex convective situations:

"For me, the best part of using the 1-min satellite imagery [in this simulation] was the ability to identify which cells to focus on by analyzing overshooting tops."

The majority of participating forecasters also observed features and their evolutions in the IR imagery they had not previously witnessed in satellite imagery from the current GOES series. One example some forecasters noted occurred between 2147 and 2159 UTC as cloud-top 


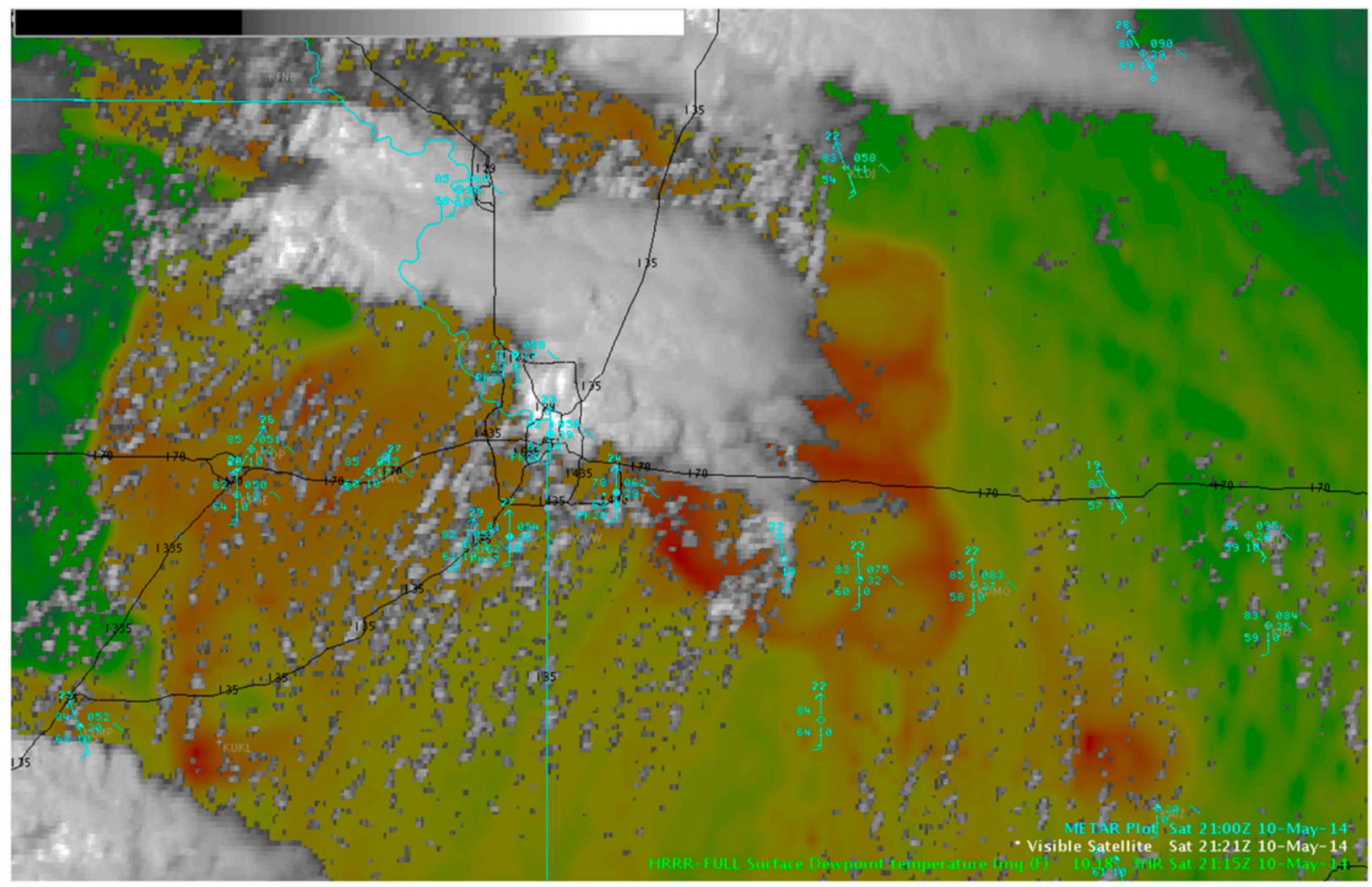

FIG. 6. GOES-14 visible satellite image valid at 2121 UTC 10 May 2014, METARS valid at 2100 UTC 10 May 2014, and the HRRR 2-m dewpoint 3.25-h forecast valid at 2115 UTC 10 May 2014.

temperatures associated with the main thunderstorm updraft not only became colder, they also became quasi stationary when compared to the mean ambient environmental flow. They hypothesized this evolution was in response to the updraft quickly strengthening while others suggested it may be an indication that updraft rotation was increasing. It is currently difficult to determine how often this occurs and if there is operational utility in being able to identify a quasi-stationary updraft.

The final key observation made during this simulation was the value of fusing multiple datasets to enhance the forecaster's situational awareness. Although this visualization capability was introduced to forecasters during the training simulation, the majority first discussed its importance during this simulation. In the Common AWIPS Visualization Environment (CAVE), the most familiar method to fuse two images is to use the image combination feature. There are visualization limitations with this method, most notably that each image is only partially visible at the same time. For this evaluation, forecasters were taught how to change the transparency for only portions of the upper-layer image so it is possible to analyze the lower-layer image in the transparent areas. For example, if a forecaster loads the 1-min visible satellite imagery and the gridded 2-m dewpoint field from the HRRR model into CAVE, the visible imagery clear-sky pixels can be made transparent to analyze the underlying HRRR field (Fig. 6). One forecaster discussed how important this AWIPS capability is:

"Data fusion was quite useful to show various parameters and their relation to satellite features. Moisture flux, CAPE, and helicity [fields] fused with satellite imagery really aided in seeing if storms were moving into more/ less favorable environments as well as which environment will be (un)favored for convective development."

The observations forecasters made during the convective simulations, many that have been presented here, led to numerous discussions on how high temporal satellite imagery may reshape the convective warning decisionmaking process in the GOES-R era. These observations would be repeated and reinforced multiple times as the week progressed, but they were first observed while forecasters completed this simulation. It is unclear to what extent the warning decision-making process will be improved by integrating satellite and radar in the GOES-R era. Identifying techniques to improve situational awareness by effectively fusing these datasets may be a rich 
source of operational research in the future. It is important to note that integrating high temporal satellite imagery into the warning decision-making process is only possible with low latency. Latency on the order of seconds, not tens of minutes, is crucial to being able to integrate the imagery in real-time convective warning operations.

RCWs completed after this simulation revealed that high temporal satellite imagery may provide value in understanding certain aspects of convective development and evolution. However, there were differences of opinion concerning its specific role for the warning decision-making process. Some forecasters asserted confidence in their ability to integrate the satellite imagery as the warning forecaster, while others were doubtful they could utilize satellite and radar simultaneously. One forecaster discussed the difficulty with internally assimilating and then using the satellite imagery for decision-making during this simulation:

"It was most difficult to incorporate 1-min satellite imagery as the warning forecaster. Not because it's not useful, but rather, when storms are firing all over the place and there's a half a dozen warnings already out, I generally fall back to what I'm comfortable with—radar data."

Another forecaster stated a similar opinion and suggested it may be more useful to have a mesoanalyst relay information to the warning forecaster:

"I think in extreme convective cases, assimilating satellite imagery into the warning process is, by far, most difficult for the warning forecaster.... The mesoanalyst can do this task, without the pressure of issuing the warnings, and feed the information to the warning forecaster so they can have greater situational awareness and subsequent confidence in their warnings."

These contrasting opinions motivated a follow-up evaluation, which focused exclusively on the challenge of integrating 1-min satellite imagery as the convective warning forecaster. This evaluation will be discussed in section 4 .

\section{c. Wildfire and air quality support}

This simulation occurred in the Reno, Nevada (REV), and Sacramento, California (STO), NWS CWAs on 22 August 2013 between 1645 and 1815 UTC and focused on monitoring the central California Rim Fire (Fig. 7; a satellite animation of this simulation is available in the online supplemental material). The Rim Fire, which began on 17 August near Yosemite National Park, nearly doubled in size on this day. During the simulation, surface winds shifted from south to southwesterly near the fire, which amplified the upslope component into the Sierra Foothills and resulted in vigorous fire growth on the eastern perimeter of the complex. In fact, pyrocumulus clouds were observed in the 1-min visible satellite imagery beginning at 1730 UTC. As a result of the rapidly expanding fire, excessive amounts of smoke were carried aloft and to the northeast into the Lake Tahoe and Reno area. Near the end of the simulation, visibility was reduced and hazardous air quality conditions were observed in the Lake Tahoe valley.

Although each forecaster had clear responsibilities during this simulation, they were asked to share meteorological insights and work together as a team. One forecaster was assigned to support the Rim Fire on-site incident meteorologist (IMET) with critical meteorological information, another was assigned to an IDSS air quality role with the fictitious Reno-Tahoe Health District, and the third was assigned to monitor three aviation sites and issue any amendments necessary to assure TAFs were representative.

Early in the simulation, the Rim Fire IMET notified forecasters that crews digging fire lines near Cherry Lake Camp, Californa, were observing pyrocumulus clouds forming to their southeast. The IMET went on to inform forecasters that the incident commander may need to modify the attack plan and move resources to another area of the fire. During each evaluation week, forecasters assigned to the IMET support role were able to quickly analyze the 1-min visible satellite imagery to provide the IMET with critical supporting information. For example, using the visible satellite imagery, forecasters could determine, in near real time, that smoke plumes on the eastern side of the fire were more buoyant than the plumes on the western edge. This gave them confidence that low-level relative humidity observations from two remote automated weather stations just within the northern fire perimeter and to the northwest of the fire (not shown) may not have been representative of the environment over the foothills to the east. One of the forecasters discussed being able to observe plume characteristics change in the satellite imagery:

"By having 1-min satellite imagery, I could see the plume characteristics change. That enabled me to identify development that was potentially threatening in time to convey sufficient warning [to the IMET]. In that situation, with a large wildfire in complex terrain, waiting another five or ten minutes could be too late. It's the difference between people escaping and people getting trapped."

During the first portion of the simulation, forecasters assigned to monitor air quality and aviation impacts in Lake Tahoe and Reno did not feel the dense smoke plume would affect those areas. However, once the character of the fire changed and pyrocumulus clouds extended into higher winds aloft, the impact quickly became apparent. Every forecaster (i.e., six forecasters, one each week) assigned to the IDSS air quality responsibility contacted the Reno-Tahoe Health District via NWSChat and issued an air quality special weather statement. One forecaster discussed this: 


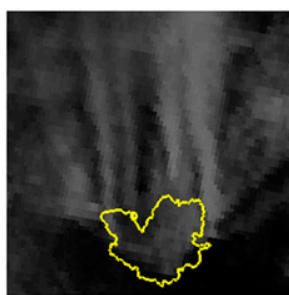

1720 UTC

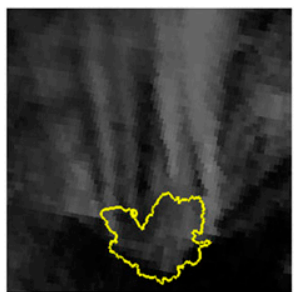

1726 UTC

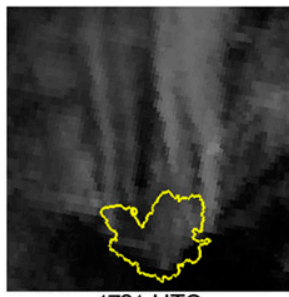

1731 UTC

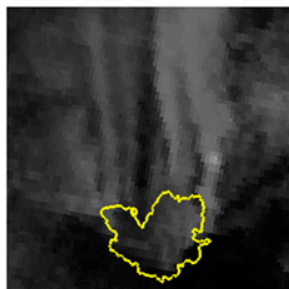

1736 UTC

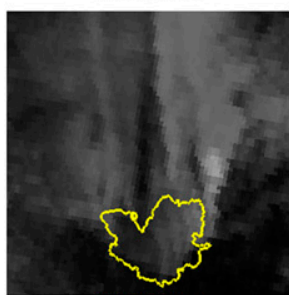

1745 UTC

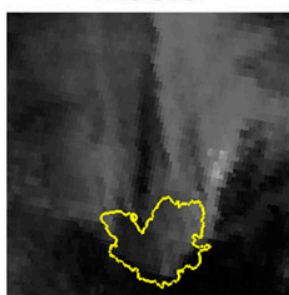

1750 UTC

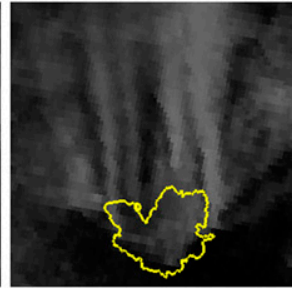

1721 UTC

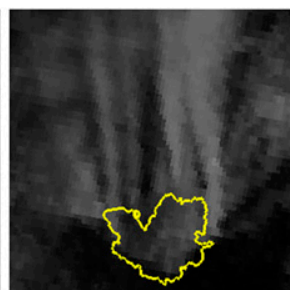

1727 UTC

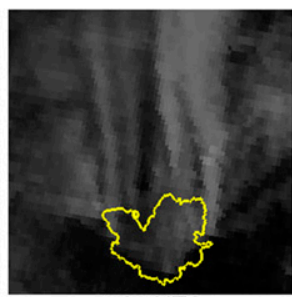

1732 UTC

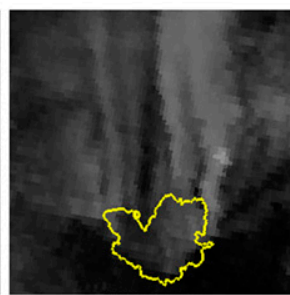

1738 UTC

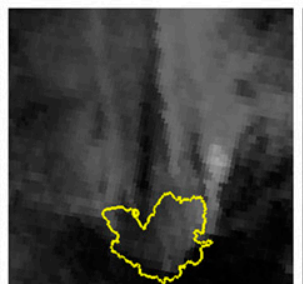

1746 UTC

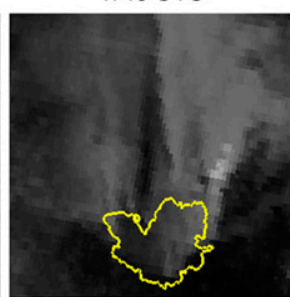

1751 UTC

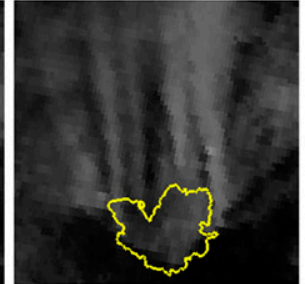

1722 UTC

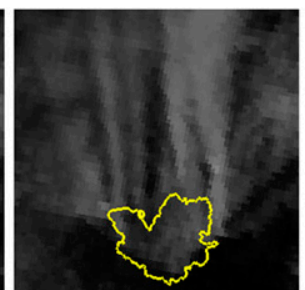

1728 UTC

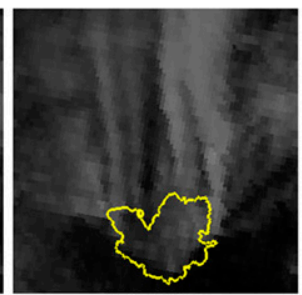

1733 UTC

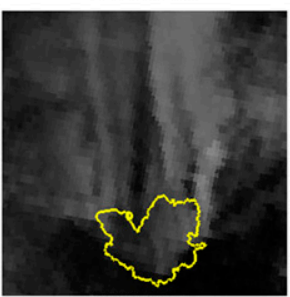

1739 UTC

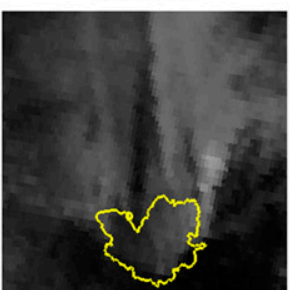

1747 UTC



1752 UTC

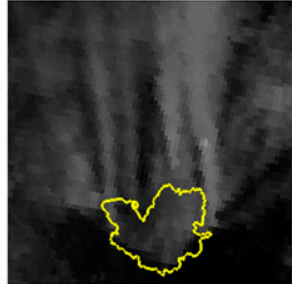

1723 UTC

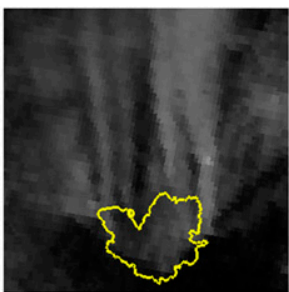

1729 UTC

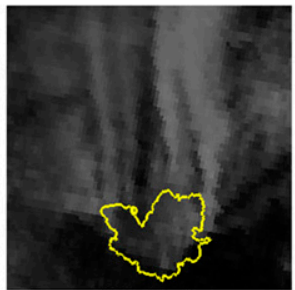

1734 UTC



1740 UTC

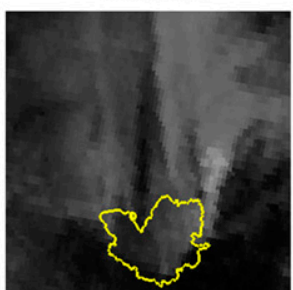

1748 UTC

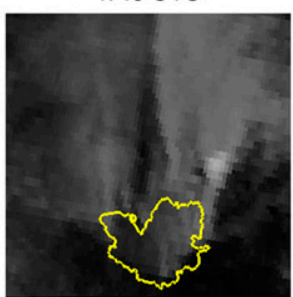

1753 UTC



1725 UTC

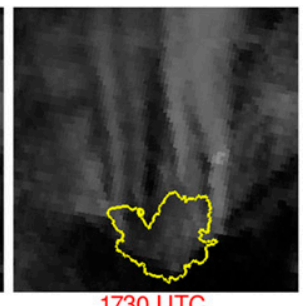

1730 UTC

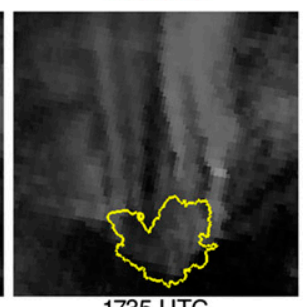

1735 UTC

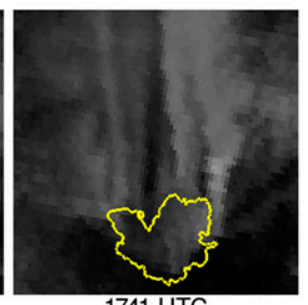

1741 UTC

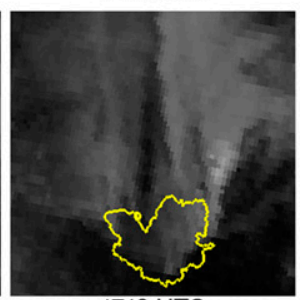

1749 UTC

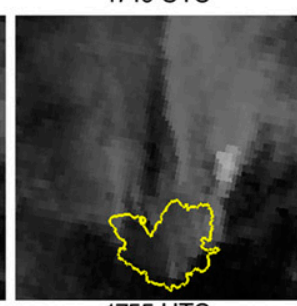

1755 UTC

FIG. 7. GOES-14 visible satellite image time series of the Rim Fire between 1720 and 1755 UTC (i.e., 30 images) 22 Aug 2013 from the wildfire and air quality support simulation. The Rim Fire active perimeter valid at 1200 UTC 22 Aug 2013 is shown (yellow), GOES-14 routine operations images have times identified in red text, and animations of GOES-14 super rapid scan and routine operations between 1645 and 1815 UTC are available in the online supplemental material. 
"The 1-min satellite imagery was definitely adding more than just confidence to my decisions; it was driving a lot of them. I was trying to get ideas from [the high-resolution] models about what time I thought the airborne smoke plume would arrive and then I would go to the satellite and compare.... It added exceptional value to my ability to collaborate with the Health District about putting out an accurate and timely Air Quality Alert."

Forecasters monitoring the smoke plume for possible TAF impacts also discussed how the 1-min satellite imagery was responsible for the majority of their decisionmaking:

"You can see the persistence of the features so much more easily in the 1-min satellite imagery. The detail makes certain aspects [of the smoke plume] so much more identifiable. In this simulation, it added to my confidence levels when coordinating and making a forecast. It also added a new dimension to situational awareness."

\section{d. Fog and low-stratus aviation support}

The fog and low-stratus aviation support simulation occurred in the San Francisco/Monterey Bay, California (MTR), NWS CWA on 22 August 2013 between 1630 and 1800 UTC and focused on providing aviation forecast support for the San Francisco Terminal (SFO; a satellite animation of this simulation is available in the online supplemental material). When the simulation began, the San Francisco Bay area was covered in an 1800-ft stratus deck, which was causing arrival delays at SFO. Around 1700 UTC, vertical mixing started to thin the stratus across the higher terrain of the Santa Cruz Mountains and by 1730 UTC expanded across the southern portion of San Francisco Bay (Fig. 8). By 1810 UTC, 10 min after the simulation ended, the stratus mixed out from SFO to San Jose, California (SJC), and the SFO METAR returned to visual flight rules (VFR) conditions at 1900 UTC. Forecasters inherited the 1200 UTC TAFs for SFO, SJC, and the Oakland International Airport (OAK) that indicated 1500-ft ceilings would clear after 2000 UTC. They were instructed to monitor the low stratus with the 1-min satellite imagery, update and amend TAFs, and, if necessary, use NWSChat to communicate ceiling changes with the SFO air traffic control tower.

Forecasters found animating the 1-min satellite imagery, with negligible data latency, invaluable to their situational awareness and decision-making while monitoring the low stratus during this simulation. Many forecasters believed that being able to observe how the mixing process evolved, drove their decisions:

"In this simulation, the satellite [imagery] was directly influencing the decisions. You couldn't make them without [using the] satellite [imagery]."
Other forecasters discussed that, when comparing 1- and 5-min satellite imagery, 1-min satellite imagery was not necessary when monitoring the low stratus:

"Looping the 1-min satellite imagery was directly influencing my decision in this simulation. I couldn't have made the call to [forecast visual flight rules which would allow the FAA to] lift the ground delay program that soon without it. But, in this case, I'm not sure 1-min [satellite imagery] was necessary. I have a feeling that I could almost make the same decision looking at 5-min versus 1-min imagery.'"

Despite the difference of opinion on whether 1-min satellite imagery was essential or if 5-min resolution imagery was sufficient, it is clear that the high-temporalresolution satellite imagery significantly impacted forecaster decisions during this simulation. During postsimulation small-group discussions or within webbased decision logs, all 17 forecasters stated that their decision to confidently update the SFO forecast to VFR conditions was driven by the 1-min satellite imagery. Furthermore, before the simulation ended at 1800 UTC, 10 of 17 forecasters documented their decision to update the SFO tower that an accelerated improvement to VFR conditions would occur prior to 1900 UTC.

In order for SFO to operate at its maximum traffic flow rate capacity (i.e., approximately 60 in-bound flights per hour), air traffic control must utilize side-by-side landings on its southeast-northwest-oriented parallel runways (Hilliker and Fritsch 1999). However, the maximum flow rate is impacted by fog and low stratus at SFO when ceilings are below $2400 \mathrm{ft}$ or visibility is less than 5 statute miles (SM). Even though supported aircraft can take advantage of simultaneous offset instrument and closely spaced parallel runway approaches to mitigate this impact, fog and low stratus still negatively affect arrivals at SFO. Therefore, not only are accurate short-term forecasts important for planning purposes, they also have an economic impact on the aviation industry. For example, one estimate provided by a Federal Aviation Administration (FAA) Command Center NWS national aviation meteorologist indicated it can cost $\$ 76$ each minute an aircraft is grounded. Applying this estimate to each of the 10 forecasters who accurately updated their short-term forecasts during the simulation can provide an economic benefit analysis estimate. Assuming that arrivals were reduced to 30 aircraft per hour when impacted by the stratus deck, VFR conditions occurring 90 minutes early would allow 45 additional aircraft to arrive at SFO. For each aircraft, if grounded an additional 90 minutes and applying the $\$ 76$ per minute estimate, the savings to the aviation industry would have been approximately $\$ 7,000$ per aircraft or $\$ 315,000$ in total. 


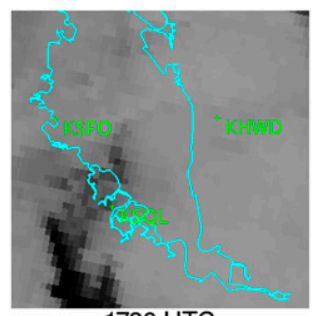

1726 UTC

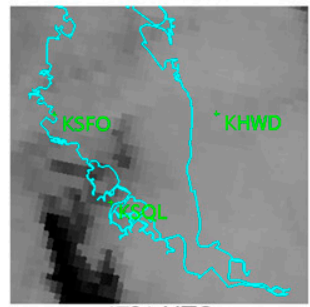

1731 UTC

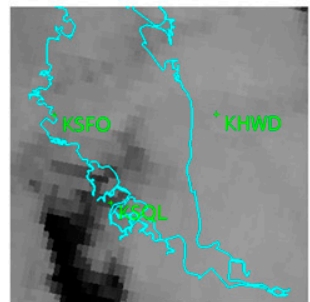

1736 UTC

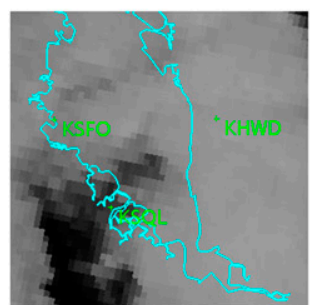

1745 UTC

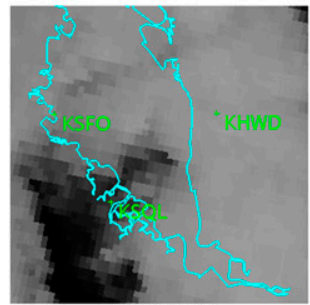

1750 UTC

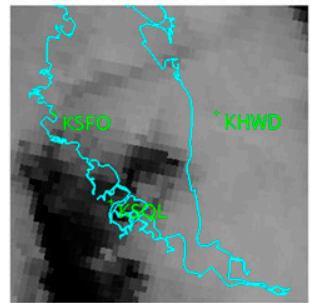

1756 UTC

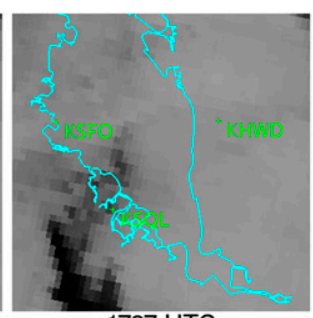

1727 UTC

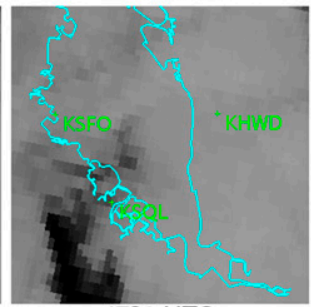

1732 UTC

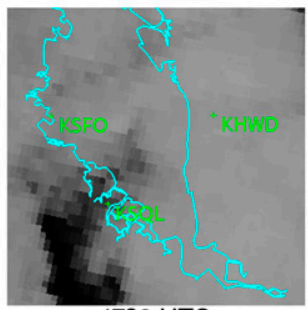

1738 UTC

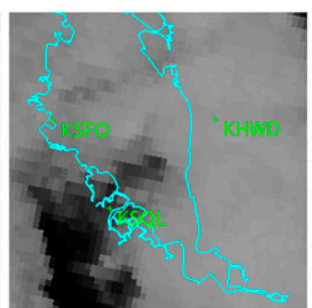

1746 UTC

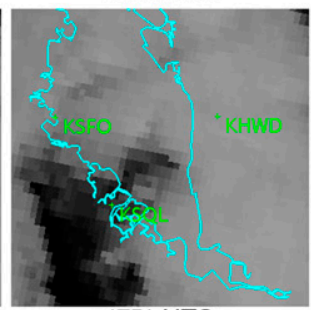

1751 UTC

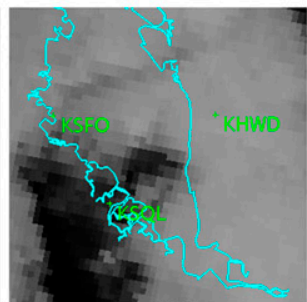

1757 UTC

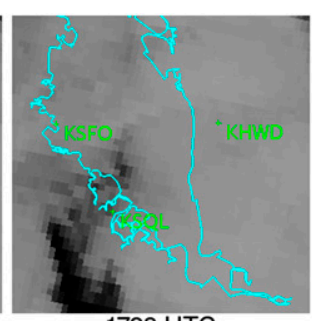

1728 UTC



1733 UTC

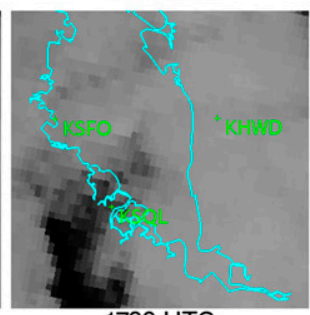

1739 UTC

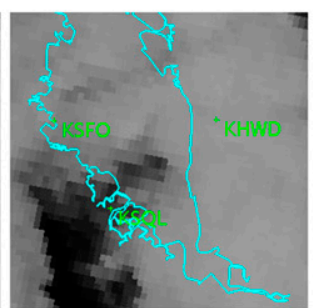

1747 UTC

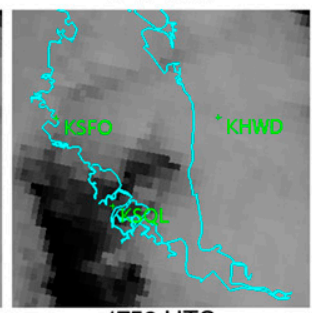

1752 UTC

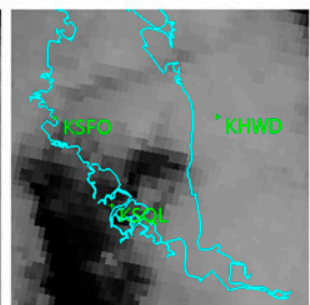

1758 UTC

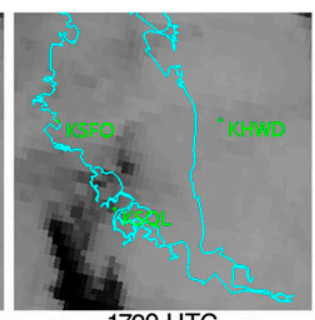

1729 UTC



1734 UTC

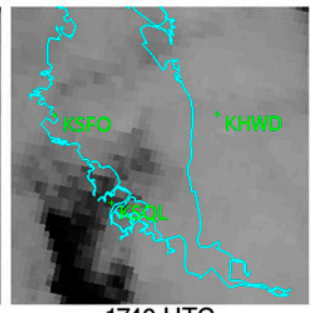

1740 UTC

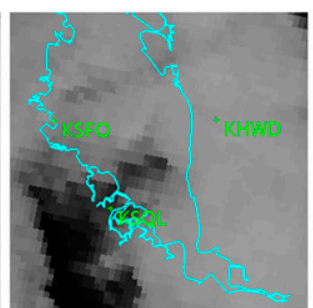

1748 UTC

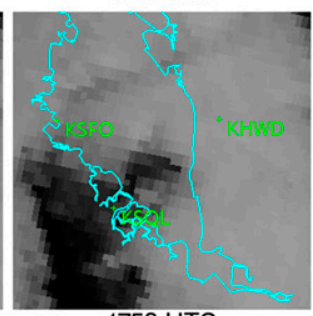

1753 UTC

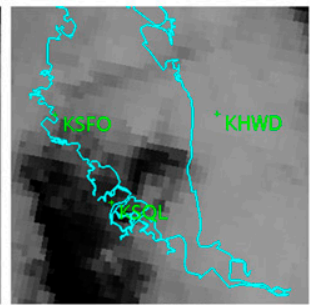

1759 UTC

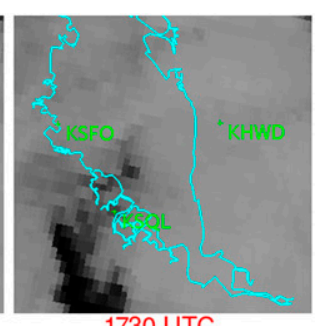

1730 UTC

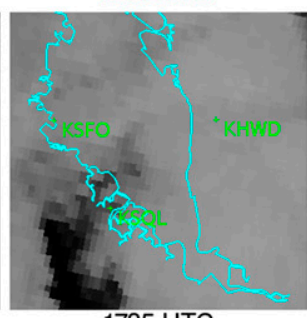

1735 UTC



1741 UTC

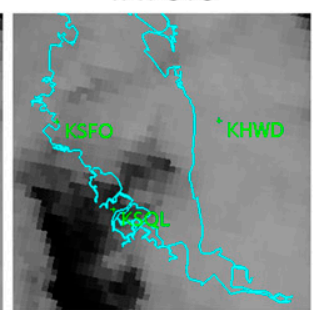

1749 UTC



1755 UTC



1800 UTC

FIG. 8. GOES-14 visible satellite image time series of southern San Francisco Bay between 1726 and 1800 UTC (i.e., 30 images) 22 Aug 2013 from the fog and low-stratus aviation support simulation. GOES-14 routine operations images have times identified in red text, and animations of GOES-14 super rapid scan and routine operations between 1630 and 1800 UTC are available in the online supplemental material. 


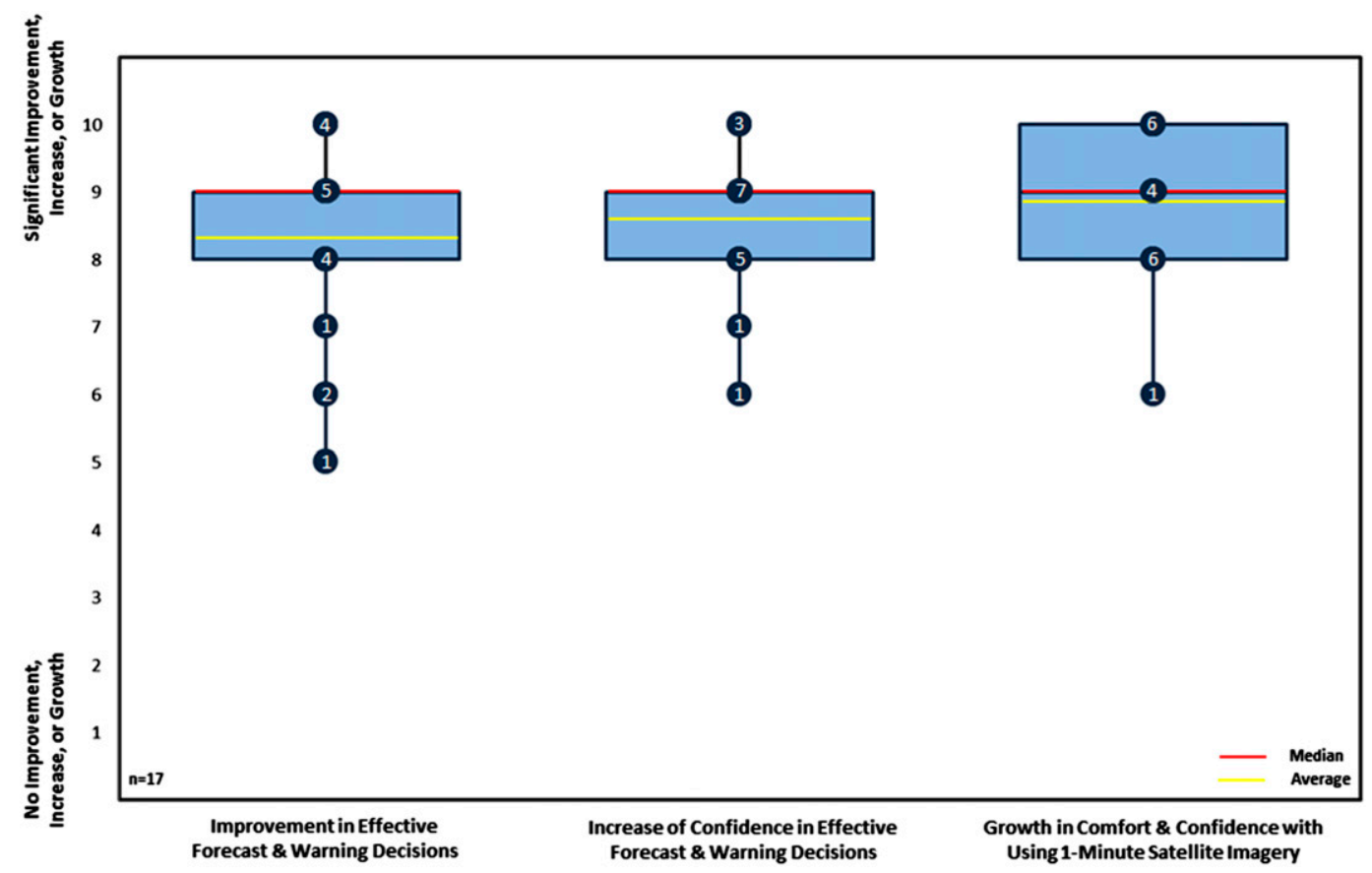

FIG. 9. Box-and-whisker plots of forecaster responses rating their improvement in effective forecast and warning decisions, their increase in confidence with making effective forecast and warning decisions, and their growth in comfort and confidence when using 1-min satellite imagery. The bottom and top of the solid blue box mark the 25th and 75 th quartiles, respectively. The yellow bar denotes the median value, the red bar represents the average value, and the values indicate the number of responses chosen for that rating.

\section{Overall results}

To conclude each evaluation week, forecasters completed a 90-min anonymous online survey that asked them to rate and discuss topics including, but not limited to, confidence, assimilation, and usefulness of the high temporal satellite imagery and derived products (i.e., CTC and OT algorithms) during the simulations. Following completion of the online survey, forecasters participated in a final group discussion with OPG facilitators.

In the first portion of the survey, forecasters rated, on a scale from 1 to 10 , if their confidence increased ( 1 being no increase in confidence and 10 being a significant increase) and if they noticed improvement ( 1 being no improvement and 10 being significant improvement) in the decisions they made using the satellite imagery during the simulations. Overall, forecasters rated their confidence and improvement in the decisions they made as having increased substantially (Fig. 9). On a scale from 1 to 10 , with 1 being no increase in confidence or improvement and 10 being a significant increase, on average the 17 forecasters rated the increase in confidence 8.59 and the increase in improvement 8.29. One forecaster stated:

"The 1-min imagery was extremely useful in making forecast and warning decisions during the various weather scenarios by improving confidence during the forecast process."
Another forecaster made an attempt to quantify the influence of satellite imagery on decisions made:

"In fact, I estimate that many of the decisions and warnings I relayed and issued this week came a lot sooner (on the order of 5-10 min) than perhaps I would have made without the 1-min satellite imagery."

Forecasters were asked to rate their increased comfort and confidence in using the 1-min satellite imagery throughout the evaluation. Fifty-nine percent of forecasters expressed a significant increase in comfort using the satellite imagery during the evaluation; only one forecaster rated their growth below 8 out of 10 (Fig. 9). Many forecasters went on to discuss how their comfort grew throughout the week:

"I learned a lot in just a few days and I am confident that further experience with the 1-min GOES-R satellite imagery will continue to improve my interpretation skills."

Another forecaster discussed how their comfort changed after integrating the 1-min satellite imagery throughout the week for convective events:

"At first, [using the 1-min satellite imagery] was a bit overwhelming. Gradually, my confidence in interpreting and applying the imagery increased. By the end of the 


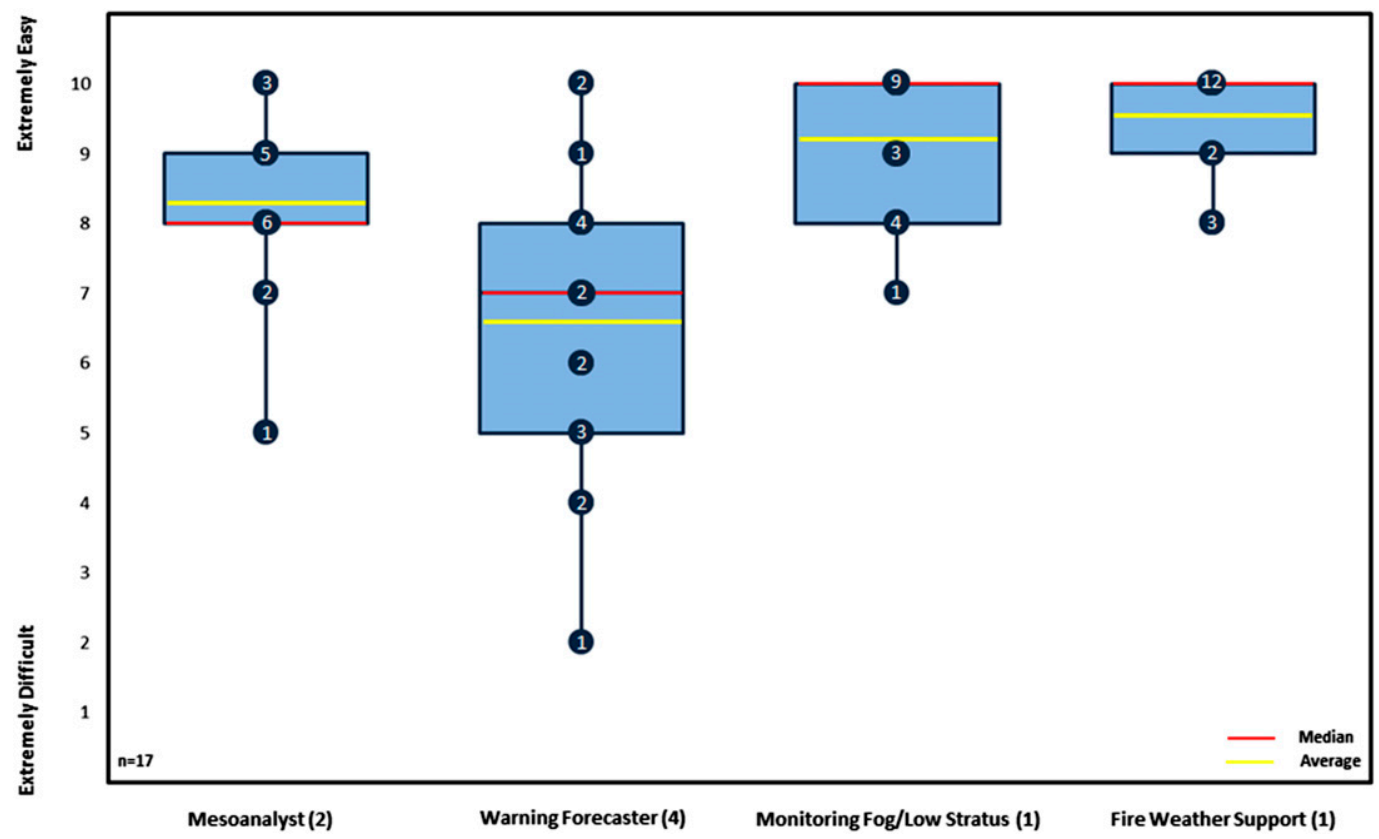

FIG. 10. As in Fig. 9, but for forecaster responses rating the ease of assimilation of 1-min satellite imagery as the mesoanalyst, as the warning forecaster, for monitoring fog and low stratus, and for providing fire weather support.

week I was completely sold on the idea of using the imagery to issue warnings, fulfill IDSS requests, and anticipate IDSS needs, etc."

These results are not surprising since evaluating a new capability can be thought of as an exercise in "learning by doing." Although readiness evaluations are not formal training exercises, forecaster comfort and understanding in using the 1-min satellite imagery does improve by repeatedly applying it in real situations. This being said, forecasters were asked how essential training resources for 1-min satellite imagery will be in the GOES-R era. All 17 forecasters rated the importance of training resources a 9 or 10 with an average of 9.76. One forecaster discussed the importance of learning how to use 1-min satellite imagery for convective applications early, when forecasters learn how to interrogate radar for the forecast and warning decision-making process in the NWS Radar and Applications Course (RAC; Warning Decision Training Division 2016):

"If you could get the [1-min satellite imagery] training in RAC, where you learn and form your habits in the earliest training you could take those habits with you the rest of your career.... To me it is almost like learning a second language. If you learn English first it will always be your primary language, but if you learn another language at the same time [as English] you become bilingual. This is similar. If you learn radar first, it is going to be your primary source [for thunderstorm interrogation] and satellite will always be second, but if you incorporate them together from the beginning it is almost like bringing up a new generation of forecasters, fluent in using both tools simultaneously.",

Overall, forecasters felt that a variety of easily accessible, focused, and well-designed training resources are crucial in being able to adopt and apply 1-min satellite imagery for forecast and warning decisions.

Finally, based on the simulations completed in this evaluation, forecasters rated how easy it was to assimilate 1-min satellite imagery for the range of tasks assigned during the evaluation. Most forecasters found it relatively easy to assimilate the satellite imagery and use it to make decisions for monitoring fog and low stratus and providing fire weather support (Fig. 10). As the mesoanalyst, the results were similar but more forecasters (three) rated the ease of assimilation as seven or below. However, as the warning forecaster, the results were much different. Ten forecasters rated the ease of assimilation below seven, and six rated it five or below. One forecaster discussed the difficulty in using the 1-min satellite imagery as the warning forecaster and why having a mesoanalyst is important for warning operations:

"I think in extreme convective cases, assimilating satellite imagery into the warning process is, by far, most 


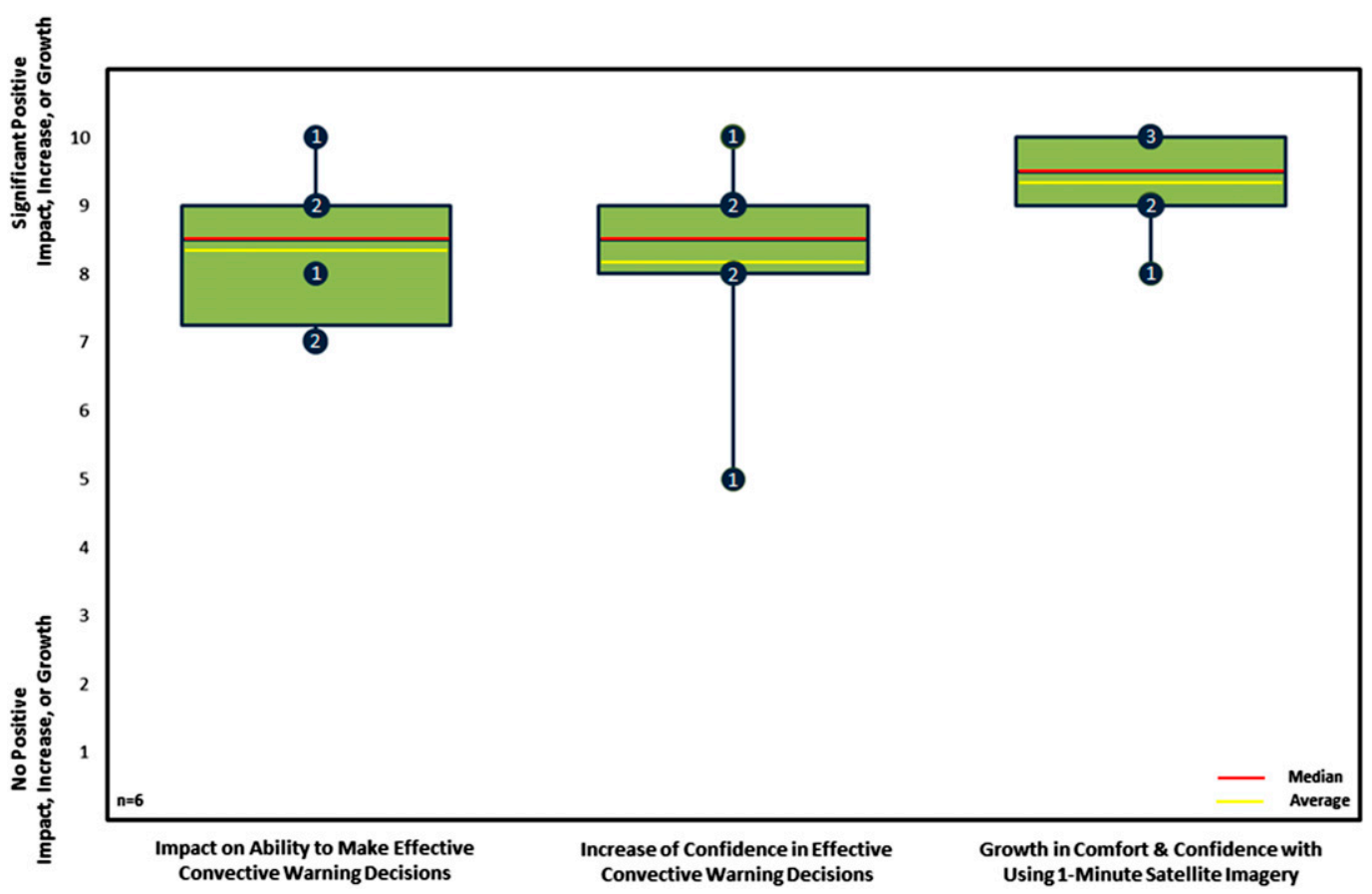

FIG. 11. As in Fig. 9, but for forecaster responses from the 2-week real-time evaluation integrating 1-min satellite imagery into decision-making as the warning forecaster.

difficult for the warning forecaster... . The mesoanalyst can use the imagery without the pressure of issuing warnings and feed that information to the warning forecaster so they can have greater situational awareness and confidence in their warnings."

Another forecaster discussed how assimilating the satellite imagery as the warning forecaster was difficult at first, but became easier the more they used it:

"The only time it seemed somewhat difficult to incorporate 1-min satellite imagery was into radar/warning operations. Since I am not used to using satellite imagery this way, it took a little adjustment to incorporate it into my operations and divert from the way warning operations are typically done. However, once I made that adjustment it was much easier to use the satellite data as a warning forecaster."

It is difficult to determine the reason that some forecasters had difficulty assimilating and integrating the imagery to help make decisions as the warning forecaster because the online survey was anonymous. It could be hypothesized that forecasters with difficulty were from locations where opportunities as the warning forecaster are limited because of the low climatological occurrence of severe convection, when compared to other areas of the CONUS. It is also possible that it is too difficult to integrate the satellite imagery into the warning decision-making process.
As a result of the discrepancy in opinions on assimilating 1-min satellite imagery as the warning forecaster, the OPG decided to continue investigating whether NWS forecasters can effectively integrate 1-min satellite imagery into the convective warning decisionmaking process. Therefore, for one week in May and another week in June 2015 during the real-time 2015 SRSOR experiment, six NWS Central Region forecasters came to the OPG to integrate 1-min satellite imagery into their decision-making as the warning forecaster. These forecasters were chosen by their WFO's management to participate because of their substantial convective warning experience. While issuing convective warnings in real time at the OPG, forecasters were asked to replicate the workload practices typical of convective warning operations with one caveat: intentionally assimilate 1 -min satellite imagery into the warning decision-making process. During each of the weeks, the forecasters completed an interactive training session on Monday afternoon, conducted real-time warning operations Tuesday-Thursday, and debriefed with OPG staff on Friday morning. Forecasters issued convective warnings in 10 NWS CWAs on days where the SPC categorical convective outlooks had slight and enhanced risks for severe thunderstorms.

Similar to the 6-week evaluation, at the end of each week forecasters completed an anonymous survey that asked them to rate and discuss integrating the 1-min satellite imagery as the warning forecaster. It was the 


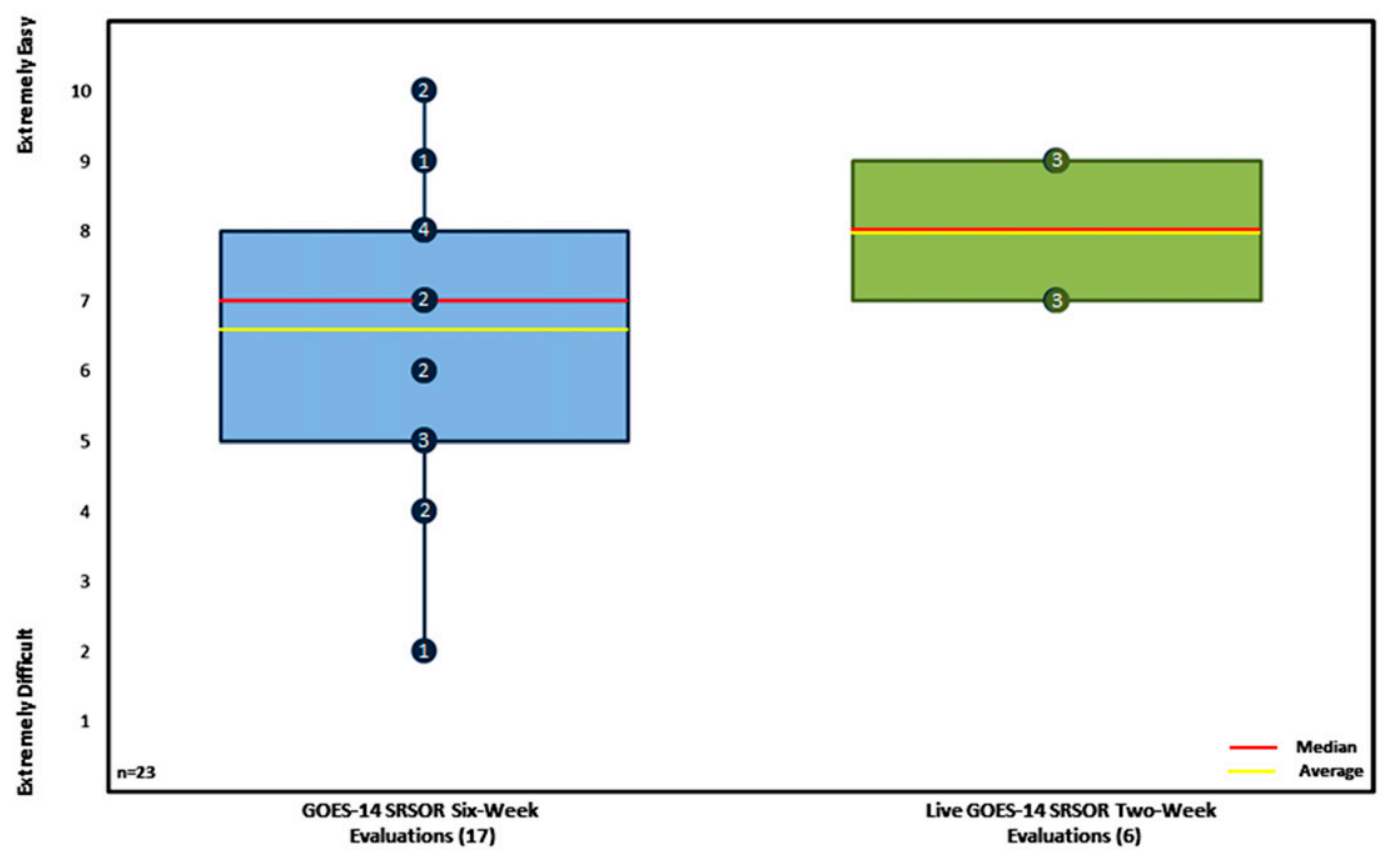

FIG. 12. As in Fig. 9, but for forecaster responses rating the ease of assimilation of 1-min satellite imagery as the warning forecaster during the 6-week evaluation and the 2-week real-time evaluations.

opinion of all six forecasters that integrating the 1-min satellite imagery had significant impact on their ability to make effective warning decisions, and all but one thought this led to increased confidence in those decisions (Fig. 11). With respect to assimilating the satellite imagery in the warning decision-making process, on a scale of 1 (extremely difficult) to 10 (extremely easy), three forecasters rated the ease of assimilating the imagery a 9 and three rated it a 7 (Fig. 12). One forecaster concluded that their ability to assimilate the imagery improved with only three days' worth of experience:

\begin{abstract}
"After working three real-time weather events as the warning forecaster, the ability to use 1-min satellite imagery and make it a part of the warning decision process became more comfortable each day. However, even on the first day I was able to quickly integrate and adapt my warning decision process with the 1-min imagery."
\end{abstract}

Another forecaster discussed what is gained by integrating the satellite imagery into warning operations:

"My confidence increased throughout the week as I compared what I was seeing on radar with what I was seeing in the 1-min satellite imagery... . Knowing there are correlations between these cloud features, associated hazardous weather, and being able to see the cloud features every minute gave me great confidence. When combining [the satellite imagery] with the radar data, I felt like I was provided with another dimension to interrogate the storms within."
Last, after using the satellite imagery for three days as the warning forecaster, in conditions analogous to WFO convective warning operations, participants were asked how confident they were integrating the imagery directly into their analysis and decision process. The responses they could choose ranged from extremely confident (i.e., they believe they could integrate 1-min satellite imagery into their radar interrogation practices to enhance convective warning decisions right now) to doubtful (i.e., even with considerable practice, they are certain that they could not integrate 1-min satellite imagery into their radar interrogation practices to enhance convective warning decisions). Three forecasters believed they could integrate the satellite imagery right now, and three others said they could integrate the imagery with just a little more practice. Not only does the feedback from these six additional NWS forecasters continue to reinforce the value of 1-min satellite imagery for interrogating deep convection, it suggests that it is possible to successfully integrate this imagery in the warning decision-making process.

\section{Findings and recommendations}

OPG evaluations are aimed at assessing the operational readiness or operational impact of new tools and capabilities that have the potential to be integrated into 
NWS forecast and warning operations. The results of these evaluations, including this one, are disseminated to NWS leadership. These reports contain recommendations related to the readiness for field implementation, unique value added for decision-making, adverse impacts on forecaster workload, and operational training. The following findings and recommendations, based on forecaster feedback discussed in sections 3 and 4, were provided to NWS leadership and the NWS Office of the Chief Learning Officer (OCLO) to support the implementation of high temporal satellite imagery into the forecast and warning process for the GOES-R era.

At the start of each evaluation week, it was suggested to participating forecasters that they consider if and how forecasters should learn to integrate 1-min satellite imagery into their workflow and decision-making. As discussed in section 4 , all participants rated the development of training resources for 1-min satellite imagery applications as an essential need. During small-group discussions, forecasters stated that this training should include a variety of focused, job-relevant, application-oriented learning resources. For example, resources should demonstrate how to interpret specific atmospheric processes in high temporal satellite imagery, integrate that imagery with radar data while interrogating convective structure, and apply that knowledge for forecast and convective warning decision-making.

As a result of the evaluation experience, forecasters recognized that many opportunities will exist for meaningful operational research in the GOES-R era. They recommend that satellite focal points are appointed at each WFO, who are responsible for advancing satellite imagery and products into the forecast process and assisting science and operations officers in encouraging, leading, and guiding this research. One possible outcome may be the development of a library that includes short, focused regional and local examples illustrating how 1-min satellite imagery can have a direct, positive impact toward improving analyses and forecasts. Contributions for this library would largely come from WFO forecasters, and it would be continuously populated with new instructive cases for the purpose of enhancing peer-to-peer application-based learning. Implementing this initiative will likely require some investment in technologies designed to streamline the process of capturing how a forecaster interacts with data within AWIPS.

These findings suggest that learning to use high temporal satellite imagery to identify atmospheric features, understand atmospheric processes, enhance forecaster decision-making, and communicate reliable impactbased hazardous weather information to NWS partners will be critical to support Weather Ready Nation goals.
Therefore, the recommendations were delivered to the NWS OCLO to be considered for inclusion into the GOES-R training curriculum, which is currently being developed by NWS instructional design professionals.

Recent efforts have been directed at integrating multiple GOES-R imagery and products with data from the WSR-88D network. Bedka et al. (2015) analyzed five convective storms to examine how satellite cloud-top observations compare with radar and lightning observations at high temporal resolution, and Gravelle et al. (2016) showed how fusing GOES-R convective products for the 20 May 2013 Moore, Oklahoma, tornado outbreak might have enhanced warning decision-making. It is clear that the frequency of satellite imagery in the GOES-R era will have significant impact on visualizing and interpreting the evolution of atmospheric threats. Forecasters found that fusing high temporal satellite imagery with other datasets, products, and decision aids (e.g., radar data, HRRR gridded output, and GIS layers) can add an additional level of depth to forecaster understanding of the atmosphere. All 23 forecasters experimented with integrating and arranging the 1-min satellite imagery on their personal AWIPS displays in order to maximize their ability to assimilate the imagery and make effective forecast and warning decisions. It is recommended that NWS resources be invested to explore and establish effective display procedures for various forecast tasks that integrate high temporal satellite imagery with numerous datasets and decision aids to enhance situational awareness.

There is increasing concern that the volume of information provided by observational datasets and high-resolution model output poses a real threat of overwhelming the forecaster. GOES-R imagery and products represent one of many high-resolution datasets that forecasters will be challenged to integrate into their decision-making. For example, in addition to GOES-R data, Multi-Radar Multi-Sensor (MRMS; Cocks et al. 2016) data, statistical algorithms for conveying calibrated probabilistic information such as the ProbSevere Model (Cintineo et al. 2014), new WSR-88D technologies such as the Supplemental Adaptive IntraVolume Low-Level Scan (SAILS; Chrisman 2013) and mesoSAILS modes (Daniel et al. 2014), total lightning data (e.g., Goodman et al. 2005), and spotter observations from the mobile Precipitation Identification Near the Ground (mPING; Elmore et al. 2014) project are all being introduced into the operational forecast environment. If forecasters are to benefit, resources and attention must be devoted toward identifying how to effectively incorporate these datasets into the operational workflow to maximize their usefulness. 
If successful, this will allow forecasters to improve their identification of meteorological threats for IDSS while minimizing the potential for this influx of information to negatively impact forecasters' workloads. Accordingly, over the next several years, it will be vital that the OPG, NOAA test beds and proving grounds, and other research-to-operations collaborators (e.g., National Severe Storms Laboratory and NASA's Short-term Prediction Research and Transition Center) invest some time and resources into investigating next-generation concepts of operation.

This comprehensive OPG evaluation attempted to answer important questions about how high-temporalresolution satellite imagery may impact NWS forecaster decision-making in the GOES-R era. Forecasters assessed the impact of the imagery during a variety of simulations while issuing convective warnings, updating TAFs, and providing IDSS to NWS partners. This evaluation determined that high temporal satellite imagery will likely have a significant positive impact on forecaster decision-making. Taking advantage of these benefits will require a fundamental change in how NWS forecasters embrace and use satellite imagery in the forecast process.

Acknowledgments. The authors are grateful for the NWS evaluation participants and their NWS Weather Forecast Office staff and management: Robert Bohlin (WFO FGZ), Brian Boyd (WFO LKN), Jim Caruso (WFO ICT), Todd Chambers (WFO BYZ), Marcia Cronce (WFO MKX), Jeff Davis (WFO TWC), Ryan Ellis (WFO RAH), Paul Frisbie (WFO GJT), Fred Glass (WFO LSX), John Goff (WFO BTV), Ryan Husted (WFO GLD), Bryan Jackson (WFO LWX), Chris Jakub (WFO ICT), Michael Kochasic (WFO GLD), Stephen Konarik (WFO MFL), Jenni Laflin (WFO EAX), Rebecca Mazur (WFO CYS), Andrew Moulton (WFO MRX), Dan Nietfeld (WFO OAX), Marc Spilde (WFO MFR), Jimmy Taeger (WFO SGX), Paul Wolyn (WFO PUB), and Eleanor Vallier-Talbot (WFO BOX). We would also like to thank Dr. Pam Heinselman (NOAA/OAR) and Katie Bowden (University of Oklahoma-CIMMS) for their guidance with facilitating recent case walk-throughs, and finally to Jack Richardson (OPG systems administrator), Matt Foster (NWS Central Region Headquarters), Greg Noonan (NWS Central Region Headquarters), and Bill Gery (NWS Central Region Headquarters) for their technical expertise with ingesting historical datasets into the AWIPS-II infrastructure. Finally, the authors are appreciative for the thorough comments and suggestions from three anonymous reviewers. This research is supported by the NOAA/STAR GOES-R Proving Ground and
CIMSS Collaboration with the NOAA/NWS/Operations Proving Ground grants under NOAAUniversity of Wisconsin Cooperative Agreement NA15OAR4590188, U.S. Department of Commerce.

\section{REFERENCES}

Andra, D. L., Jr., E. M. Quoetone, and W. F. Bunting, 2002: Warning decision making: The relative roles of conceptual models, technology, strategy, and forecaster expertise on 3 May 1999. Wea. Forecasting, 17, 559-566, doi:10.1175/ 1520-0434(2002)017<0559:WDMTRR>2.0.CO;2.

Bedka, K. M., R. Dworak, J. Brunner, and W. Feltz, 2012: Validation of satellite-based objective overshooting cloud-top detection methods using CloudSat cloud profiling radar observations. J. Appl. Meteor. Climatol., 51, 1811-1822, doi:10.1175/JAMC-D-11-0131.1.

_ C. Wang, R. Rogers, L. D. Carey, W. Feltz, and J. Kanak, 2015: Examining deep convective cloud evolution using total lightning, WSR-88D, and GOES-14 super rapid scan datasets. Wea. Forecasting, 30, 571-590, doi:10.1175/WAF-D-14-00062.1.

Bluestein, H. B., E. W. McCaul Jr., G. P. Byrd, R. L. Walko, and R. Davies-Jones, 1990: An observational study of splitting convective clouds. Mon. Wea. Rev., 118, 1359-1370, doi:10.1175/1520-0493(1990)118<1359:AOSOSC >2.0.CO;2.

Bowden, K. A., P. L. Heinselman, D. M. Kingfield, and R. P. Thomas, 2015: Impacts of phased-array radar data on forecaster performance during severe hail and wind events. Wea. Forecasting, 30, 389-404, doi:10.1175/WAF-D-14-00101.1.

Chrisman, J. N., 2013: Dynamic scanning. NEXRAD Now, No. 22, Radar Operations Center, Norman, OK, 1-3. [Available at http:// www.roc.noaa.gov/WSR88D/PublicDocs/NNOW/NNow22c.pdf.]

Cintineo, J. L., M. J. Pavolonis, J. M. Sieglaff, and D. T. Lindsey, 2014: An empirical model for assessing the severe weather potential of developing convection. Wea. Forecasting, 29, 639653, doi:10.1175/WAF-D-13-00113.1.

Cocks, S. B., S. M. Martinaitis, B. Kaney, J. Zhang, and K. Howard, 2016: Multi-Radar Multi-Sensor (MRMS) quantitative precipitation estimation: Initial operating capabilities. Bull. Amer. Meteor. Soc., 97, 621-638, doi:10.1175/BAMS-D-14-00174.1.

Crandall, B., G. Klein, and R. R. Hoffman, 2006: Working Minds: A Practitioner's Guide to Cognitive Task Analysis. The MIT Press, $332 \mathrm{pp}$.

Daniel, A. E., J. N. Chrisman, S. D. Smith, and M. W. Miller, 2014: New WSR-88D operational techniques: Responding to recent weather events. Proc. 30th Conf. on Environmental Information Processing Technologies, Atlanta, GA, Amer. Meteor. Soc., 5.2. [Available online at https://ams.confex.com/ ams/94Annual/webprogram/Paper241216.html.]

Dworak, R., K. M. Bedka, J. Brunner, and W. Feltz, 2012: Comparison between GOES-12 overshooting-top detections, WSR-88D radar reflectivity, and severe storm reports. Wea. Forecasting, 27, 684-699, doi:10.1175/WAF-D-11-00070.1.

Elmore, K. L., Z. L. Flemig, V. Lakshmanann, B. T. Kaney, V. Farmer, H. D. Reeves, and L. P. Rothfusz, 2014: mPING: Crowd-sourcing weather reports for research. Bull. Amer. Meteor. Soc., 95, 1335-1342, doi:10.1175/BAMS-D-13-00014.1.

Goodman, S. J., and Coauthors, 2005: The North Alabama Lightning Mapping Array: Recent severe storm observations and future prospects. Atmos. Res., 76, 423-437, doi:10.1016/ j.atmosres.2004.11.035. 
Gravelle, C. M., J. R. Mecikalski, W. E. Line, K. M. Bedka, R. A. Petersen, J. M. Sieglaff, G. T. Stano, and S. J. Goodman, 2016: Demonstration of a GOES-R satellite convective toolkit to "bridge the gap" between severe weather watches and warnings: An example from the 20 May 2013 Moore, Oklahoma, tornado outbreak. Bull. Amer. Meteor. Soc., 97, 69-84, doi:10.1175/BAMS-D-14-00054.1.

Heinselman, P. L., D. S. LaDue, and H. Lazrus, 2012: Exploring impacts of rapid-scan radar data on NWS warning decisions. Wea. Forecasting, 27, 1031-1044, doi:10.1175/WAF-D-11-00145.1.

D. M. Kingfield, and R. Hoffman, 2015: Tornado warning decisions using phased-array radar data. Wea. Forecasting, 30, 57-78, doi:10.1175/WAF-D-14-00042.1.

Hilliker, J. L., and J. M. Fritsch, 1999: An observations-based statistical system for warm-season hourly probabilistic forecasts of low ceiling at the San Francisco International Airport. J. Appl. Meteor., 38, 1692-1705, doi:10.1175/1520-0450(1999)038<1692 AOBSSF $>2.0 . \mathrm{CO} ; 2$.

Line, W. E., 2014: GOES-R Proving Ground demonstration at the Hazardous Weather Testbed 2014 Spring Experiment final evaluation. NOAA/Hazardous Weather Testbed Rep., 36 pp. [Available online at http://www.goes-r.gov/users/ docs/pg-activities/PGFR-HWT-2014-Final.pdf.]

_ , T. J. Schmit, D. T. Lindsey, and S. J. Goodman, 2016: Use of geostationary super rapid scan satellite imagery by the Storm Prediction Center. Wea. Forecasting, 31, 483-494, doi:10.1175/ WAF-D-15-0135.1.

Mazur, R. J., J. F. Weaver, and T. H. Vonder Haar, 2009: A preliminary statistical study of correlations between inflow feeder clouds, supercell or multicell thunderstorms, and severe weather. Wea. Forecasting, 24, 921-934, doi:10.1175/ 2009WAF2222149.1.

NOAA, 2013: Weather-ready nation roadmap. NOAA/NWS, 75 pp. [Available online at http://www.nws.noaa.gov/com/ weatherreadynation/files/nws_wrn_roadmap_final_april17.pdf.]
- 2015: GOES-R Series Ground Segment (GS) Project Functional and Performance Specification (F\&PS). GOES-R Proving Ground Rep. 416-R-FPS-0089, 298 pp. [Available online at http://www.goes-r.gov/resources/docs/GOES-R_GS_FPS.pdf.]

Schmit, T. J., M. M. Gunshor, W. P. Menzel, J. J. Gurka, J. Li, and A. S. Bachmeier, 2005: Introducing the next-generation Advanced Baseline Imager on GOES-R. Bull. Amer. Meteor. Soc., 86, 1079-1096, doi:10.1175/BAMS-86-8-1079.

— to prepare for GOES-R. J. Appl. Remote Sens., 7, 073462, doi:10.1117/1.JRS.7.073462.

_ cant events: Preparing users for the next generation of geostationary operational satellites. Bull. Amer. Meteor. Soc., 96, 561-576, doi:10.1175/BAMS-D-13-00210.1.

Sieglaff, J. M., L. M. Cronce, W. F. Feltz, K. M. Bedka, M. J. Pavolonis, and A. K. Heidinger, 2011: Nowcasting convective storm initiation using satellite-based averaged cloud-top cooling and cloud-type trends. J. Appl. Meteor. Climatol., 50, 110-126, doi:10.1175/2010JAMC2496.1.

$\ldots, \ldots$, and _ 2014: Improving satellite-based convective cloud growth monitoring with visible optical depth retrievals. J. Appl. Meteor. Climatol., 53, 506-520, doi:10.1175/JAMC-D-13-0139.1.

Terborg, A., 2014: Aviation Weather Testbed - Final evaluation. GOES-R Proving Ground Rep., 27 pp. [Available online at http://www.goes-r.gov/users/docs/pg-activities/ PGFR-AWC-2014-Final2.pdf.]

Warning Decision Training Division, cited 2016: The Radar \& Applications Course (RAC). NOAA/NWS. [Available online at http://www.wdtb.noaa.gov/courses/rac/index.php.]

Weaver, J. F., and D. Lindsey, 2004: Some frequently overlooked severe thunderstorm characteristics observed on GOES imagery: A topic for future research. Mon. Wea. Rev., 132, 1529-1533, doi:10.1175/1520-0493(2004)132<1529: SFOSTC $>2.0 . \mathrm{CO} ; 2$. 